$\xi=-1$

\title{
Effect of Complex Structural Material Coated the Flight Body to Measure the Absorption of Radar Radiation at Different Elevations of Flight Latitude
}

\author{
Abbas Ali Mhmood Karwi ${ }^{1 *}$ \\ ${ }^{1}$ Al-Furat Al- Awsat Technical University, Babylon Technical Institute, Iraq \\ *E-mail: abbas30032002@Yahoo.com
}

\begin{abstract}
Avoiding radar detection is a prime importance in several fields. We design multi reinforced polymeric materials to absorb radar waves, these materials have low density, high elastic modulus, high tensile strength good erosion resistance and good fatigue strength. Composite materials are made by three principle techniques, injection, spraying and compression. Jet technique was used to measure materials resistance for erosion. We find that polytetrafluroethylene with multi mixtures has the best specification than other polymeric materials. We manufacture twenty-one alloys (A, B, C, D, E, F....W) used in this work. Composite materials (A-W) are making by adding fillers to matrices. Absorption coefficient of fillers and matrices was evaluated and measured alone or as a composite. Dynamic and static radar cross section shapes (eight shapes)were studied in this work. The better shapes for absorption waves are (spherical, conical, cylindrical, and parabolic). All parameters controlled reflectivity and absorption were studied. We found that the maximum rate of absorption is more than (70\%), this percent observed in certain coating layers. Metallurgical and mechanical work on composite materials have been investigated. Model designed to compute multi variables affecting on absorption and reflection.
\end{abstract}

Keywords: Shapes, detection, Composite, Parameters, Reflection.

\section{Introduction}

Radar cross section is the measure of a target's ability to reflect radar signals in the direction of the radar receiver, it is a measure of the ratio of backscatter power to the power density that is intercepted by the target. The RCS of a target can be viewed as a comparison of the strength of the reflected signal from a target to the reflected signal from a perfectly smooth sphere of cross sectional area of $1 \mathrm{~m}^{2}$. The conceptual definition of RCS includes the fact that not all of the radiated energy falls on the target. A target's RCS is most easily visualized as the product of three factors, these factors are, projected cross section, reflectivity, and directivity. All objects illuminated by radar will reflect energy to some extent. The radar cross section is a parameter denoted by used to characterize the scattering properties of a radar target. It represents the target's size as seen by the radar and has the dimensions of square meters. RCS area is not the same as physical area, but a measure of a target's ability to reflect radar signals in the direction of the receiving antenna. RCS is defined as an area intercepting that amount of power which, when scattered isotropically, produces at the receiver a density which is equal to that scattered by the actual target. In general, the RCS of a target is a function of the polarization of the incident wave, the angle of incidence, the angle of observation, the geometry of the target, the electrical properties of the target and the frequency of operation. Thus, two targets with the same physical size and shape could have considerably different radar cross-section. The scattering characterized by the radar cross section can be categorized into four main mechanisms, the first is; direct scattering, normal to flat surfaces and edges, the second is; diffractive scattering from edges and surface discontinuities, the third is; creeping waves, and the fourth is; indirect scattering from structures or cavities. Generally, the direct and diffractive mechanisms account for the majority of the radarscatter. However, the direct scattering is normally much larger than its diffractivecounterpart. The shape of the object is decisive in this respect. If the object has a flat side facing the radar transmitter it will reflect more energy than an object of any other shape. A flat plate has however almost no RCS except when aligned directly toward the radar. Corner reflectors on the other hand, have RCS almost as high as the flat plate but over a wider angle, i.e. over \pm 60 degrees. The return from a corner reflector is analogous to that of a flat plate always being perpendicular to the transmitting and receiving antenna. Targets such as aircraft often have many corners. Creeping waves can travel around the edges of the target and back toward the receiver, interfering constructively or destructively with other backscatter, depending on the travel distance. This phenomenon mostly occurs at long wavelengths. The target however must be greater than a certain minimum size, in terms of wavelength of the radiated energy, to produce a reasonable reflection of energy. Generally targets must have a size greater than about a quarter of the radar wavelength being used before a detectable echo is received. Thus for the detection of small objects, the radar wavelength must also be small, i.e. the frequency must be very high. Indirect scattering is due to multiple reflections and is common for complex structures. It is difficult to determine when this sort of scatter occurs. Typical causes of multiplescattering are rotating parts and engine cavities. 


\section{Experimental Work}

Polymeric materials were received as powders. The main three techniques adopted to manufacture the composite materials are; the first is injection technique carried out in many workshops of kerbala government, the second is; spray pyrolysis technique was carried out at Babylon university- physical department on spraying system, and the third is; compression technique was carried out at Technical Institute of Babylon - mechanical department on compression molding system manufactured for this purpose. injection moulding process has vertical and horizontal machines. The granules are continuously melted in heated cylinder and injected intermittently in to the mould. Many moulds were manufactured with different shapes such as; square, triangular, cylindrical, circular, conical, spherical and parabolic. The injection force is maintained (2ton) with temp. $\left(100-130^{\circ} \mathrm{C}\right)$ until the material has set sufficiently so as not to flow out the mould when the pressure is released. In this way voids are prevented. Complex mould cause materials containing fibers and fillers to show marked orientation. Glass fiber and thermoplastic mixture are introduced into the mould separately. Injection process has good dimensional accuracy and can be made with smooth and glossy, textured or engraved fur face depending on the inside surface of the mould. Casting products with different shapes were examined on a bistatic radar system to show the activity of injected targets on absorption and make the comparison with the other techniques. Spray pyrolysis technique used for mass production to spray wide areas; also it is a suitable for materials, which has high melting points. Sample [Al-Li base alloy] was heated before spraying process begun to (15min) to avoid shrinkage of material which causes due to difference in temperature between metal and material. To keep metal's temperature constant during operation, the time interval between two spraying process must be not increase than $(38 \mathrm{sec})$. In addition, solvent temperature must be kept constant $\left(220-240^{\circ} \mathrm{C}\right)$ measured continuously by thermocouple. The maximum distance between orifices of sprayer and sample is $(30-35 \mathrm{~cm})$, the volumetric rate of spraying is $\left(2 \mathrm{~cm}^{3} / \mathrm{min}\right)$. The maximum pressure to permit flowing is $\left(3 \mathrm{~kg} / \mathrm{cm}^{3}\right)$, the pressure must be kept constant. Film layer must be left (1-2min) until chemical reaction completed, then it has taken to be examined on radar system. Compression moulding technique is the third technique used in this work, the production of this procedure are not good enough in comparison with the products of other techniques. Product's surface was rough in comparison with the smooth surface of products made by spraying and injection procedures. Dies of mould must be machined carefully to get high quality surfaces compression method is easier and cheaper than other methods. Procedure of operation is easy enough, heating source such as burner was used to heat the mould until reaching $\left(250^{\circ} \mathrm{C}\right)$, grains of polymer founded into mould are melted slowly or it took long time to reach melting. The melted mixture (fillers \& matrices) was compressed strongly to take the mould's shape. Moulds were machined to seven shapes represented the (RCS) shapes with different sizes, thicknesses to study the effect of radar waves on these shapes formed by compression technique. There are nineteen materials used as fillers. The mixture of polymeric materials with these fillers forms the final composite material. There are thirteen polymeric material used as matrices when mixed the fillers. Fillers have taken many shapes such as ; grains , powders , pins, fibers, panels, dishes, lattices, covers, adhesions, magnets and light oil. There are twenty one targets (AW), each target has special construction which contained variable fillers with the certained (wt\%) of fillers and matrices. There are seven standard shapes (sq-sph) Each target manufactured with the seven shapes; sample (A) for example made with the seven shapes, each shape constructed with the a certained (wt\%) of fillers and matrices, all these examined on radar system to show the effect of construction (wt \%) materials on absorption and evaluated the absorption coefficient. Absorption coefficient was evaluated for each filler alone and matrices also. Absorption coefficient of the constructed composite material was calculated. There are two basic types of radar transmitter configurations on is the self excit- ed oscillator exemplified by the magnetron, the second uses low stable power oscillator, which is turn amplified to the required level by one or more amplifier tubes. The magnetron device is likely found in applications where small size and portability. The essential parts of magnetron consists of a large block of copper (anode) into which holes and slots are cut, these holes and slots serve as resonators. The emitter or cathode consists of a cylinder of oxide- coated material. The electrons interact with the $(\mathrm{dc})$ electric field and the resulting power $(0.3$ watt) is directly connected to a pyramidal horn antenna wave guide by a coaxial transmission line. The magnetron types is $(6058 \mathrm{~B} / 1$ - Marconi instruments LTD). The energy emitted from magnetron transmitter device is guided from the transmitter through various components to the antenna or from the antenna through other components to the receiver by means of transmission lines. In our device, there are two types of lines used: a-coaxial transmission line. b- wave guide transmission line. Coaxial line is capable of guiding voltage/current from one point to another, the most popular cable used in our device is (UNIRADIO 67 50-ohm). The line carried energy over a wide range of frequencies from microwave bands to $18 \mathrm{GHz}$ at various power levels. The operating frequency range is (8$12.5 \mathrm{GH} \mathrm{z}$ ), at this range the attenuation constant $(\alpha)$ equals to $40 \mathrm{db} / 100 \mathrm{ft}$ and the rate of power transmitted is $(0.3 \mathrm{watt})$, so that we can say that this line is useful only when low power is handle or where the loss is acceptable. The power rating can be improved by increasing the dimensions of these coaxial lines. The worked wave guide type is GW-16/copper alloy used at X- band designation. In most radar applications, the enclosed metal wave guide is one of the most used types of transmission lines. the power is transmitted along the interior of the guide with particular electric and magnetic field configurations. The transmission parameters and modal characteristics are strongly dependent on the shape and the dimensions of the cross section. A rectangular guide, usually with a width (a) to height (b) ratio near $2: 1$. The dimensions of the wave guide are usually chosen to suit the operating frequency range. The operating range is usually restricted to $(8-12.5 \mathrm{GHz})$, at this range the attenuation constant $(\alpha)$ is restricted to $(0.087$ $0.067 \mathrm{dh} / 100 \mathrm{ft}$ ). The pyramidal horn as shown in Fig (4) is flared in two planes, the first is (E-plane) which has a uniform amplitude distribution, the second is ( $\mathrm{H}$ - plane) which has semi- cosine amplitude distribution, these two planes are termed the principle planes of the horn. Length of the flare depending on factors such as the band width, horn aperture, and gain. The horn is fed by a rectangular wave guide, the horn aperture dimension is $(8 \times 8 \mathrm{~cm})$ pyramidal horn used as an antenna for transmitting electromagnetic waves and receiving the reflected waves from the target Intensity of reflection measured by VSWR device. The electromagnetic wave traveling along a transmission line, if the transmission line is loaded with an impedance equal to it's characteristic impedance, the line is said to be matched and no energy will be reflected from the load, if the load impedance is not perfectly matched, some energy will be reflected from the load, another factor introduces mismatches into the transmitting line loading to the antenna is discontinuities components such as junctions, wave guide components (flange- couplings, bends, twists, filters, etc), these factors causes, that some of energy will be reflected from the load, resulting in either loss from the system, or distortion of the phase properties of the wave, the reflected wave with either added to or subtract. A bistatic radar system used in this work, it consists of two separated systems, i.e., transmitter and receiver. A transmitter type (6058B- single source- 500mA- Marconi instrument) is placed at one site and the associated receiving equipment type (6953A$160 \mathrm{~mA}$ - Marconi instrument) is placed at another as shown in Fig(4). Detection was based upon target reflections received at the receiving site. Tested samples have different shapes sizes and thicknesses. Thermometer was attached to each examined sample for measuring any change in temperature during operation. The adjusted angle to get (100\% reflectivity) must be measured and supported. Range arrival's angle and frequency must be known. The time needed for each run is $(45 \mathrm{~min})$ Distances between transmitter - target- receiver were changed at each test to observe 
the effect of range and factors related to it on absorption. The two main testes which employed are, reflectivity and penetration. Reflectivity test cases are (1R) as shown in Fig (1), (2R) as shown in Fig (2), and (3R) as shown in Fig (3), these are regarded as the idealized cases, the positions of transmitter and receiver in this case were changed at the same time until arrival's angle becomes $\left(180^{\circ}\right)$. Maximum reflectivity was obtained as a result to change the positions of transmitter and receiver. Operation was beginning supporting (Al-Li) base metal alloy to obtain (0dbw), i,e (100\% reflectivity) in certain position. (0dbw) means, the radar waves were totally reflected from forward surface. This had been taken as the standard level of power and hence, any power measured can be expressed below the standard level. Any sample recorded (Odbw) was considered to be very bad so it reflect all waves falled (100\% reflectivity). Excellent sample was recorded (-10dbw), i.e (0\% reflectivity) these samples have the highest ability to absorb waves. Samples (A-W) were constracted of fillers and polymers. Absorption coefficient of fillers, matrices and mixture were estimated. Penetration cases are $(1 \mathrm{P}, 2 \mathrm{P}, 3 \mathrm{P}, 4 \mathrm{P}$, and $5 \mathrm{P})$ as shown in Figs (5 and 6). Horn of transmitter device was supported at a suitable sites and receiver's horn was changed from $[(\mathrm{Dr}=0)$ to $(\mathrm{Dr}>\mathrm{Dt})]$. The tested samples were connected to thermocouple for evaluated temperature. Temperature changed from $\left(0.2-0.4^{\circ} \mathrm{C}\right)$, this means that the tested sample was absorbed energy and convert it to heat. At all cases of penetration, arrival's angle took to be $\left(180^{\circ}\right)$ and is $\left(0^{\circ}\right)$ Distances between transmitter- target and receiver varied at each case of testing. The main aim of penetration test is to examine the ability of composite materials with different shapes, thicknesses and sizes to absorb energy at frequency range $(8-12 \mathrm{GHz}) / \mathrm{x}-$ band designation. Distance was an important factor affected on absorption energy; also thickness of tested samples was an important parameter on absorption. Shape of samples was regarded the more effective parameter on absorbed radar waves, that the curvature shapes absorbed energy more then the plane shapes. Composite materials were tested alone with out metal base alloy to show its ability for absorption as mentioned above. Jet technique system was used to evaluate the erosion rate of composite materials.

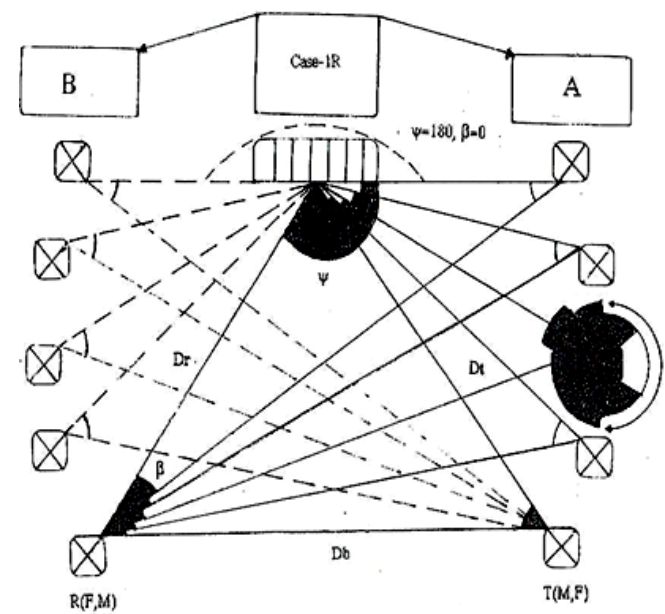

Fig. 1: Reflectivity test ( case-1)

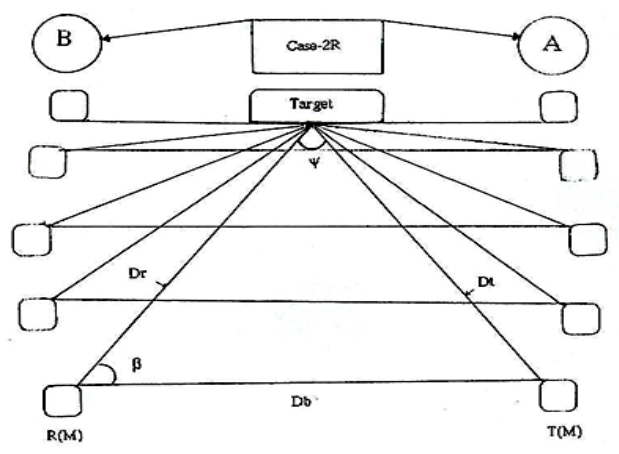

Fig. 2: Reflectivity test ( case- 2)

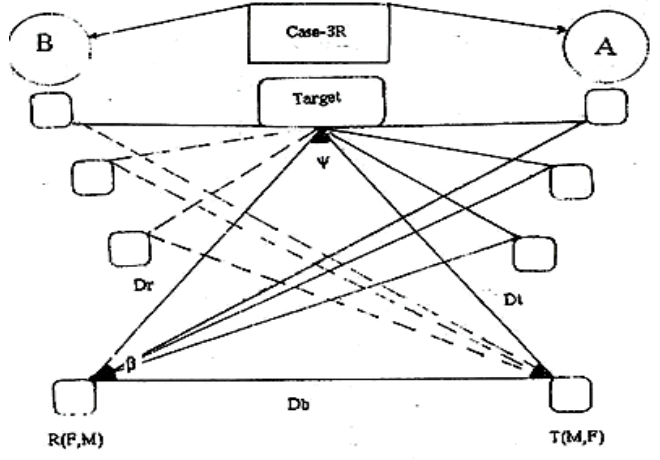

Fig. 3: Reflectivity test ( case- 3 )

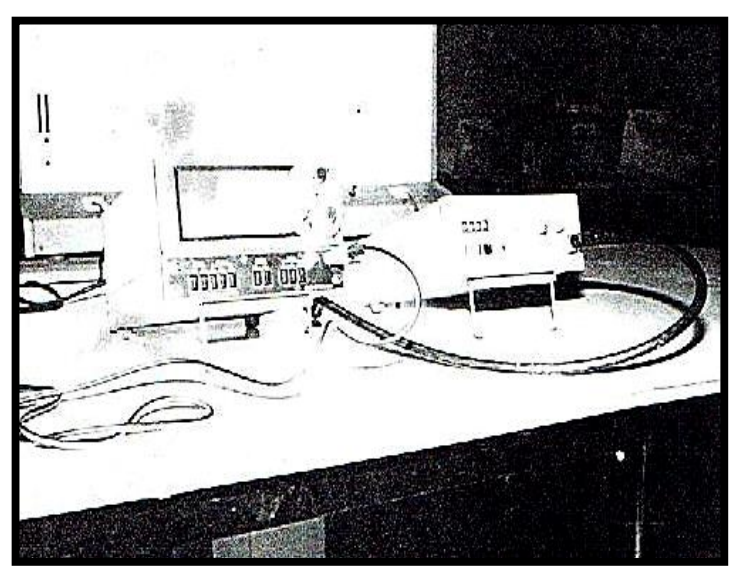

Fig. 4: Bistatic radar system

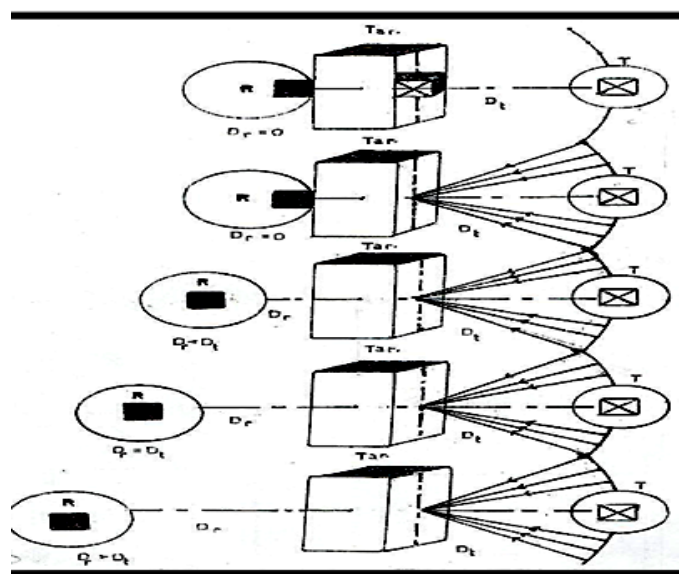

Fig. 5: Schematic representation of the six penetration cases

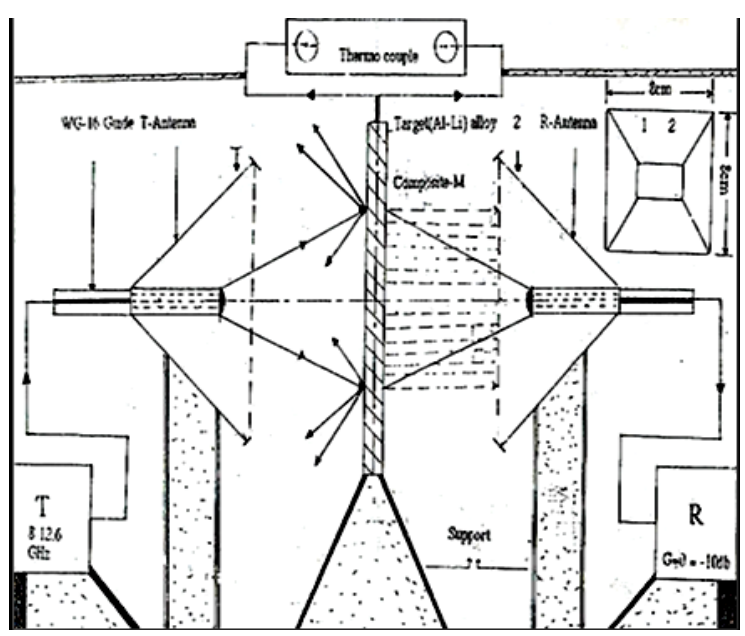

Fig. 6: Schematic representation of penetration test 


\section{Results and Discussion}

Fixing procedure was proposed and regarded as the most important factor that most be studied. The first important aim was to look for a material of best absorption. The second purpose is to find the suitable procedure to fix these materials on aircraft's surface. The outer surface was divided to many small square sector. Each sector is drilled to make a small diameter orifices. Groups of (Al-Li) wires then passed through it and distributed over the surface for a certain extent. These distributed wires are connected to each other if necessary to form large square lattice on the surface. Spraying pyrolysis technique or injection moulding technique may be used to form the covered reinforced polymeric material which protect the outer surface from radar detection. Layers of absorbed materials were arranged in such away and pressed with the high force and make connecting, the other connection procedure was done by pins or rivets which connected aircraft's metal with the composite materials. Distribution of these rivets must be designed to resist stresses which may be appears during flight. The two procedure of connection must be suited with the composite material type, which used as protection cover. Fixing procedure was an important aim after choosing the absorbed material. The two procedures Targets were basically (Al-Li) base alloy coated with the composite polymeric materials (matrix of polymers + fillers) These targets were exposed to radar waves, attenuation was recorded for all the examined targets. An increase in absorption coefficient is recorded in this sequence $\left(3^{*}, 4^{*}, 11^{*}, 13^{*}, 10^{*}, 9^{*}, 8^{*}\right.$, $\left.5^{*}, 7^{*}, 2^{*}, 6^{*}, 1^{*}\right)$. Similar behavior is apparently appear when using fillers alone as shown in fig (4-2), i.e. $(11,1,13,12,6,5,4$, $3,2,7,8,9,10,14,15,16,17,18,19)$. Highest absorption was observed when fillers $(11,12,13,1,4)$ were added to polytetrafluoroethylene (P. T. F. E). Lower attenuation was recorded when the same fillers mixed with the polyamide (P. A) Polymers No. $\left(3^{*}, 4^{*}, 11^{*}, 13^{*}\right)$ when mixed with (P.T. F. E) give higher attenuation than these polymers when mixed with (P. A) or (P. E) In general, mixture of polymers recorded higher attenuation than that recorded by composites. Target composition was regarded the most important factor affecting on attenuation. Several samples were tested, i. e. twenty one specimens. The highest coefficients were displayed by samples (B, D, G, R and X), while others, i.e. $(\mathrm{E}, \mathrm{K}, \ldots$, etc) were generally low for different shapes. Spherical, parabolic, conical and cylindrical shapes possess high tendency to absorb waves, especially samples (B, D, G, R and X). This test also reveal the shorter wave lengths were easily absorbed. Although the main purpose of this work is to search for a material which absorbed radar waves, but it is worthwhile to consider the effect of design on absorption. Target with the square shape has a very wide area compared to the beam dimensions. Once again twenty one samples were tested. They were coated with the material and of the same thickness on seven shapes (sq., tri., ..., etc). Certain composition on different shapes were examined. Highest absorption was in samples for different shapes, especially cylindrical, conical, parabolic and spherical, others samples, however, gave lower values in this sequence. Erosion is the most important test that must be done at different environmental conditions during flight. Erosion test carried out on erosion testing machine for different polymers to check it's ability on resisting erosion. Polymers were reinforced by different (wt\%) of fiberglass to find the highest material for resisting erosion. (P.A) gives lower resistance than (P.T.F.E) and (P.E). Increasing reinforcement for different shapes $(20 \%, 30 \%, 40 \%)$, P. T. F. E is the best polymer. For certain polymer, the increase in reinforcement, (P.A) and (P. T.F.E) were better in resistance, but (P.E) gives opposite results. Substantial attenuation to the incident wave was observed. For several fillers and absorption coefficient was recorded. Absorption however is based on distinct ways, i. e. scattering and true absorption. There two processes together make up the total absorption. The scattering of magnetic waves by an atom is almost similar in many ways to the scattering of visible light by dust particles in the air. It took place in all directions and since the energy in the scattered beams dose not appear in the transmitted beam, so it is said that it is absorbed. The true absorption is caused by electronic transmission with in the atom and it is best considered from the view point of the quantum theory of radiation. If a quantum of magnetic waves of sufficient energy is incident on an atom it knock a k- electron out of an atom thus cause the emission of k- characteristic radiation. The ejected electron is called a photoelectron and the emitted characteristics radiation is called fluorescent radiation. Therefore, we can say that the incident waves are partially or totally absorbed. However, not only transition of an electron occur but spin orientation may also took place when radar wave interact with the materials. Therefore, the variation of absorption of the tested materials can be attributed to the number and distribution of electrons. Waves may also be absorbed due to intermolecular processes, it is known for instance that, polymer pipes exposed to (ultraviolet) or even sunlight suffer deturation of properties due to change of type of bounding, i.e. linear bounding changes to cross linking (increase in hardness) which may cause cracking changing of bounding type, usually, involved motion of monomers i.e. this motion required energy which is absorbed from the incident beam. Other workers used ultrasonic waves related the attenuation of the polymers viscosity, thermal conductivity, scattering and intermolecular processes pointed out that thermal conductivity and scattering where of negligible effect. They also found that intermolecular processes where responsible for the attenuation. They also found an increase in the overall size of the molecule in the path of waves. The increase in absorption coefficient of matrices $(3 *, 4 *$, $\left.11^{*}, 13^{*}\right)$ is due to structural changes associated with the formation of mixture molecular interaction between pieces. It is well established that it is possible to mix the polymer to improve it is properties such as, strength , thermal stability, erosion resistance. Therefore alloying was conducted, it appears that alloying also improved absorption when mixing types of polymers with P.T.F.E, P.A, P.V.C and H.D.P.E. The observed variation in $a b-$ sorption of polymers with P. T. F. E. , P.A, P.V.C and H.D.P.E due to alloying process can be attributed to changes in density, types of bonds and structural changes. High density of (P.T.F.E) with in term molecular processes test caused between hydrogen bonds and fluoride forming large molecules against path of wave, so it gives high values of attenuation than other as shown in polymers $\left(3^{*}, 4^{*}, 10^{*}, 11^{*}, 138\right)$ with (P.T.F.E). Clorid with the hydrogen bonds in (P.V.C) gives lower values. Absorption also is connected with the loacal modes of motion (segmental conformation change and cooperation whole molecule movement. Because of the existence of strong inter molecular interactions with in the polymer, it should be possible to observe cooperative movement of large section of macromolecules in high frequency range. Hydroxyl groups in polymer are forming inter and intra molecular hydrogen bonds in addition to recrystallization process through intermolecular processes. Filler $(11,1,13,4,5,6)$ give acceptable values of attenuation, also attenuation in creased when mixed with polymers. Polytetrafluroethelene gives the best values when mixed with above fillers. Fillers have different shapes and types such as, graphite, fiber glass, glass powder, carbon fiber, iron powder, panels,...ect. Absorption coefficient for the above fillers are measured. Fiber glass and graphite have the higher values. Graphite added mainly to improve properties of polymer such as, electrical conductivity, strength, thermal stability and environmental resistance. It also foundedat this work that it cause more absorption to magnetic waves. This is particles induces internal eddy currents which gives higher values of absorption. Fiber glass may chosen for several reason. They are for instance the most important composites. Fiber glass with the fabric and matrix forms are used to reinforce material, this reinforcement increased the ability of folding, electrical and thermal isolation, lightness of material and absorption energy. The reinforced material have high specific strength and high specific modulus but have high sensitivity to environmental effects, especially moisture. Fiber are holed the external force and loads, so the applied force are transferred to fiber by shear traction. Fiber's length must be long enough to protect the material from distortion, that distortion is transferred along the large portion of fiber's length. Reinforced polymers with this 
fiber gives the maximum absorption, that fiber glass or glass in general processes an ability to absorb energy, this energy is represented, as heat which is consumed in rearranging the monomers. It gives higher values of absorption. Glass powder used to examine as much choice are possible. It gives an absorption of about (50\%) of that of fiber glass. This is expected due to discontinuity. The weight percentage is almost similar to that of fiber glass, i.e. $(10 \%)$. Iron powder gives absorption of about $(35 \%)$ of that of fiber glass. This low absorption is probably due to low percentage, i.e. $(3-5 \%)$. High values were rejected to avoid increasing weight. Absorption by iron powders is due to the inducing of eddy currents in these tiny particles. For the same reason, polymers reinforced by the were used to protect the outer parts of radar system. In addition, they improve thermal and electrical conductivities. Iron pins and panels show absorption (20\%) in comparison with the fiber glass. The effect of stacking direction of these pins and panels was also investigated, little effect was observed. The mechanism of absorption is similar to that of iron powder, i.e. energy was dissipated as eddy current and hence heat. In these cases, more space or gaps are available of wave passage.Several shape were embedded individually in the matrix, i.e. dishes and hexagonal, square and rectangular lattices. Absorption in the order of (20$25 \%$ ) of that of fiber glass was recorded. The same fiber reinforce polymer was used to examine the influence of design in absorption, parabolic shape is the better it gives attenuation in the order of $(90-100 \%)$ of the incident waves, Other shapes absorbed energy in this sequence, spherical, conical, cylindrical, circular and square. Sharp edges of some above shapes may play as a real's and re- radiate waves. Absorption coefficient of shapes produced by spraying technique is better than that produced by injection technique. This attributed to high homogeneity of samples, Large thickness samples can be produced by injection techniques $(0.5$ $1.5 \mathrm{~cm})$ it can't be produced by spraying procedure because of spilling of deposited layer increasing thickness produced an increase in absorbed by (5-15\%) due to loss of energy through it. Samples for all shapes give better absorption due to composition of it's structural sample (A) posses better results others. The presence of graphite (3-10\%) with fiber glass (10\%) and poly tetraluoroethylene give the highest values of absorption coefficient. Samples with different shapes (sq..,sph.) thicknesses $(0.5-1.5 \mathrm{~cm})$ at $(8-12.5 \mathrm{GHz})$ give the best values of attenuation, Other samples fall in this sequence. Target position (arrivals angle and range) is the strong parameter affecting on absorption. Target becomes out of detection at a region $\left(0-40^{\circ}\right)$, we can called this region as (Adead Region), that the distance was very near between the transmitter and receiver the detection was impossible. When arrival's angle increased, path increased also, causes the decreased in absorption energy. On the other side, when the range increased, the coefficient was decreased due to the decrease in radar cross section, it becomes far from the detection by radar waves. There are five penetration cases carried out. Targets with different shapes and compositions were tested. The standard thickness needed for testing is $(0.5 \mathrm{~cm})$. samples with the parabolic shape were the better due to it's shape which scattering waves and posses high tendency to absorb energy. Samples manufactured either by injection or spraying technique. Five samples with different compositions $/ 0.5 \mathrm{~cm}$ thickness were tested. Samples gave better values when manufactured with the a parabolic, spherical and conical shapes, design of conical, spherical and parabolic shape help to disperses wave at different directions in addition to type of composite material covered the tested. In this work pattern shapes were used to record the ability of target to absorb waves like oscillator. Shapes with out sharp edges recorded high attenuation values when distributed on $\mathrm{X}$-axis in addition to composition of composite material. Parabolic, spherical and conical shapes samples recorded the best attenuation than others, especially those manufactured by spraying technique due to homogeneity and smooth surface. Solid shapes recorded better results than hollow for testing. At all cases of testing smooth surface give higher attenuation due to it's ability to disperse waves. Weight loss increases with the exposure time. The minimum weight loss is exhibited by (P. T. F. E), it has the best erosion resistance in comparison with the other materials, it's weight loss after $(30 \mathrm{~m}$ in ) for instance is only $(7 \%)$ of that of (P.A). P.T.F.E provide a high temperature up to $\left(311 \mathrm{C}^{\circ}\right)$ results in increased erosion resistance. Organic materials with high temperature are relatively high in modules of elasticity and compressive strength. These properties contributes to either erosion resistance in the subsonic environment. On reinforcing P.T.F.E (20\%, 30\%, and $40 \%$ ) the weight loss decreased once again. This is due to it's stress - strain characteristics and response to loading associated with the impact weaken the stress pulse and protect the substrate. With the increasing reinforcement $(20 \%-40 \%)$, the weight loss decrease. Erosion resistance of (P.A) is lower then others. This due to the presence of fiber reduces chunking out and breakage in to small piece by providing a discontinuous path for shock transmission through the material (P.A) is brittle. If reinforcing in creased, erosion resistance increased also. (P.E) (unrein and rein for.) is one of thermo plastic materials which posses high resistance against erosion. (P.E) has lower values of resistance than (P.T.F.E) but has higher values that (P.A). (P.E) exhibit sufficiently ductile (Plastic) response to the impinging droplet loads to deform on the surface with little weight loss during the subsonic exposure. Erosion resistance decreases with the increasing reinforcement $(20 \%-40 \%$ 0 ) if reinforcement is added. The radially flowing compressed portion of the impinging drop interacts with the fiber reinforcement and breaks out pieces of fiber and matrix. In general elastomeric coating provide greater subsonic erosion protection than other brittle polymeric coatings. Fixing procedure is regarded as the most important factors that must be studied. After founding the best materials in absorbing, the second important aim is to find the suitable procedure for fixing it on airplane's surface. The outer surface is divided in to many small sectors and making offices in the middle of these sectors. Groups of wires passed through these offices and distributed over each sector. The connection with each other then be done. By using one of the two technique, sprayed or casting, the polymeric material (PA, PE, and P. T. F. E) was sprayed or injected on airplane's surface to form the final shape of the covered material which gives best absorption against radar waves. The procedure of fixing must be storage enough to resist all environmental parameters. Volumetric percentage of samples (A-W) is shown in Tables (1-21). Composition of samples (A-W) with (matrices and fillers) is shown in Tables (22 and 23 respectively). Gain, power ratio of (fillers, matrices, and main matrices) is shown in Tables (24,26,27 resp). Fillers dimensions is shown in Table (25). Attenuation for mixture is shown in Table (28).Fig (7) Show the effect of coated layer on target cross section for different target shapes with constant thickness and constant wavelengths.

Table 1: Font Specifications for A4 Papers

\begin{tabular}{|c|c|c|c|c|c|c|c|}
\hline Shape & $\begin{array}{c}\text { Square } \\
\text { rectangle }\end{array}$ & Triangle & Cylinder & Come & Circle & Parabola & Sphere \\
\hline Group & B1.2 & B3 & B4 & B5 & B6 & B7 & B8 \\
\hline Weight(s)* & 400 & 380 & 500 & 450 & 375 & 500 & 500 \\
\hline Weight(h)(gm) & -- & -- & 150 & 100 & -- & -- & 80 \\
\hline Density(s) & 5.5 & 9.7 & 0.36 & 0.99 & 6.6 & 1.45 & 0.55 \\
\hline Density(h) $\left(\mathrm{gm} / \mathrm{cm}^{3}\right.$ & -- & -- & 15.9 & 31.8 & -- & -- & 76.9 \\
\hline Volume (s)** & 72 & 36.5 & 13.57 & 454 & 56.5 & 32.4 & 904.7 \\
\hline Volume $(\mathrm{h})\left(\mathrm{cm}^{3}\right)$ & -- & -- & 9.4 & 3.14 & -- & -- & 1.04 \\
\hline $\begin{array}{c}\text { Filler No.\& Mat. } \\
\text { No*** }\end{array}$ & & & Vol. \% & & & & $\mathrm{Wt} \%$ \\
\hline 1 & & & & & & & 10 \\
\hline $5^{*}$ & & & & & & & 5 \\
\hline $.6 *$ & & & & & & & 5 \\
\hline 7* & & & & & & & 2.5 \\
\hline $8^{*}$ & & & & & & & 2.5 \\
\hline 9* & & & & & & & 5 \\
\hline 6 & & & & & & & 5 \\
\hline 7 & & & & & & & 10 \\
\hline 8 & & & & & & & 10 \\
\hline 11 & & & & & & & 2 \\
\hline 13 & & & & & & & 5 \\
\hline $13 *$ & & & & & & & 40 \\
\hline
\end{tabular}




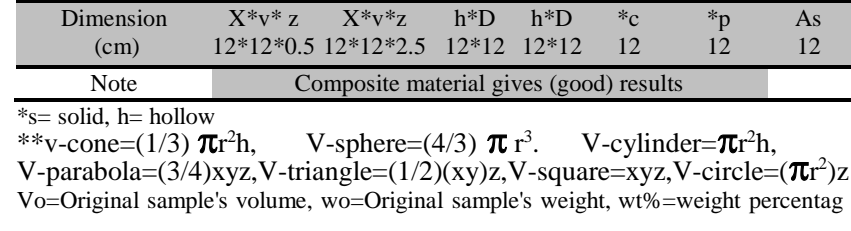

Table 2: Volumetric percentage of fillers of shape (B)

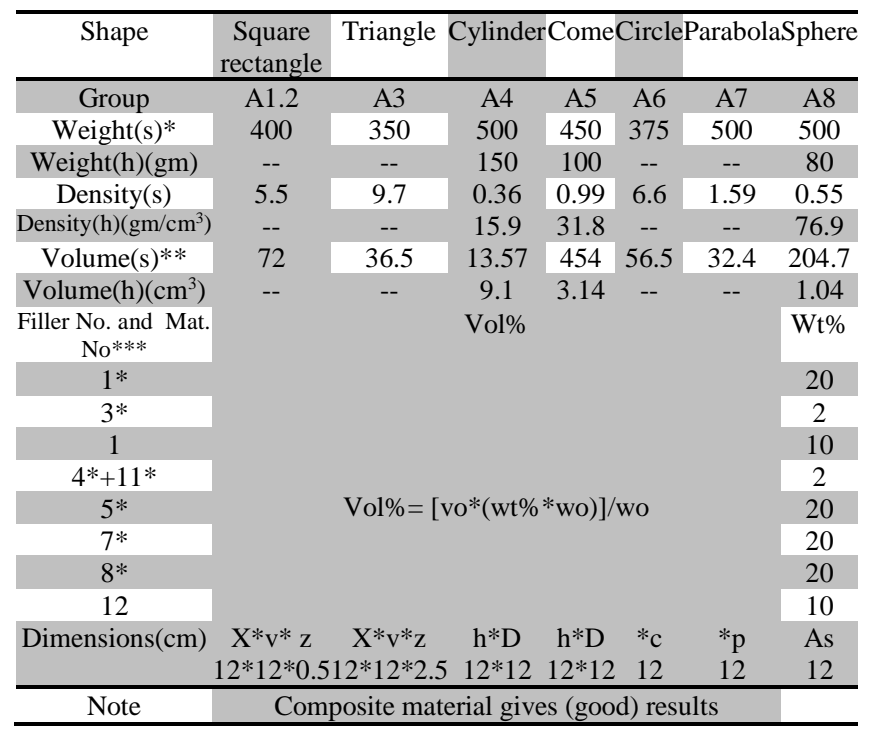

Table 3: Volumetric percentage of fillers of shape (C)

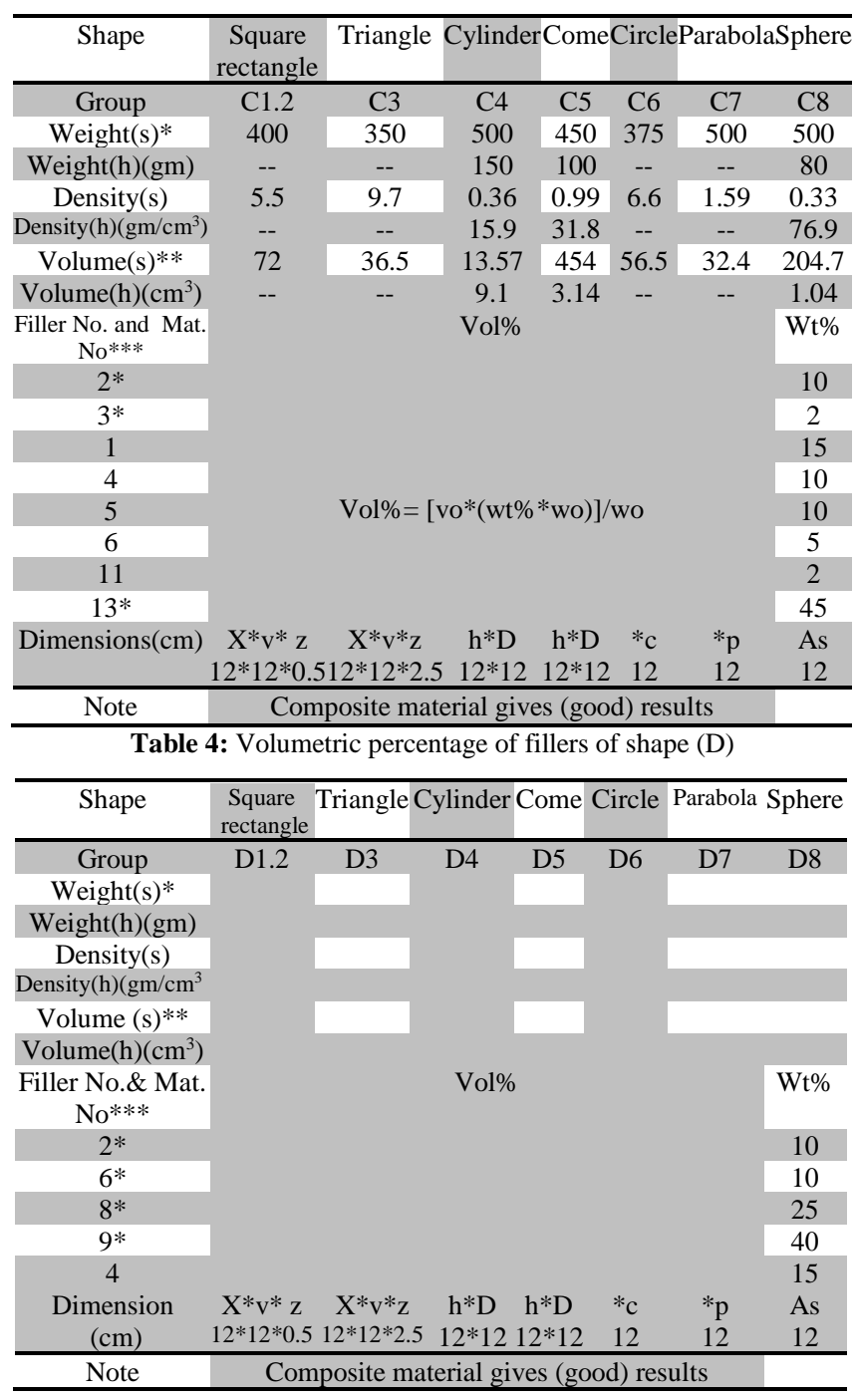

Table 5: Volumetric percentage of fillers of shape (E)

\begin{tabular}{|c|c|c|c|c|c|c|c|}
\hline Shape & $\begin{array}{l}\text { Square } \\
\text { rectangle }\end{array}$ & Triangle C & Cylinder & r Come & Circle & Parabola & Sphere \\
\hline Group & \multirow[t]{13}{*}{ D1.2 } & D3 & \multirow[t]{7}{*}{ D4 } & D5 & \multirow[t]{13}{*}{ D6 } & \multirow[t]{2}{*}{ D7 } & \multirow[t]{2}{*}{ D8 } \\
\hline Weight(s)* & & & & & & & \\
\hline \multicolumn{5}{|l|}{ Weight(h)(gm) } & & & \\
\hline \multicolumn{5}{|l|}{ Density(s) } & & & \\
\hline \multicolumn{5}{|l|}{ Density $(\mathrm{h})\left(\mathrm{gm} / \mathrm{cm}^{3}\right.$} & & & \\
\hline \multicolumn{5}{|l|}{ Volume $(\mathrm{s})^{* *}$} & & & \\
\hline \multicolumn{5}{|l|}{ Volume $(\mathrm{h})\left(\mathrm{cm}^{3}\right)$} & & & \\
\hline \multirow{2}{*}{\multicolumn{3}{|c|}{$\begin{array}{l}\text { Filler No.\& Mat. } \\
\qquad \text { No*** }\end{array}$}} & & & & & \\
\hline & & & & & & & \\
\hline $1 *$ & & & & & & & 20 \\
\hline $5^{*}$ & & & & & & & 20 \\
\hline $9^{*}$ & & & & & & & 20 \\
\hline 14 & & & & & & & 40 \\
\hline Dimension & $\mathrm{X}^{*} \mathrm{v}^{*} \mathrm{z}$ & $\mathrm{X}^{*} \mathrm{v}^{*} \mathrm{z}$ & $h * D$ & $h * D$ & $* \mathrm{c}$ & $* \mathrm{p}$ & As \\
\hline$(\mathrm{cm})$ & $12 * 12 * 0.5$ & $12 * 12 * 2.5$ & $12 * 12$ & $12 * 12$ & 12 & 12 & 12 \\
\hline Note & Con & nposite ma & aterial g & ives $(\mathrm{gc}$ & ood) $\mathrm{r}$ & ults & \\
\hline
\end{tabular}

Table 6: Volumetric percentage of fillers of shape $(F)$

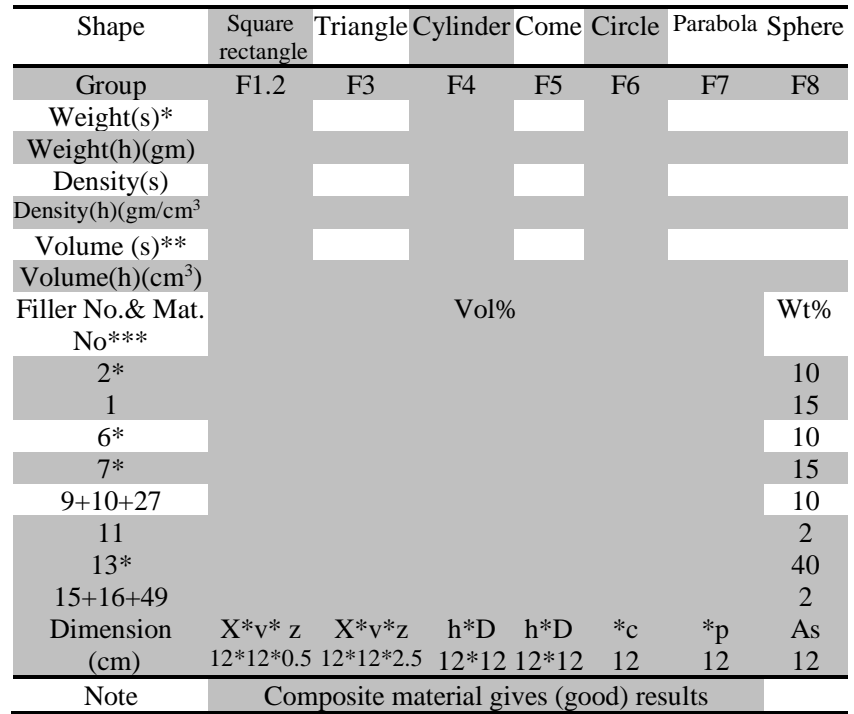

Table 7: Volumetric percentage of fillers of shape $(G)$

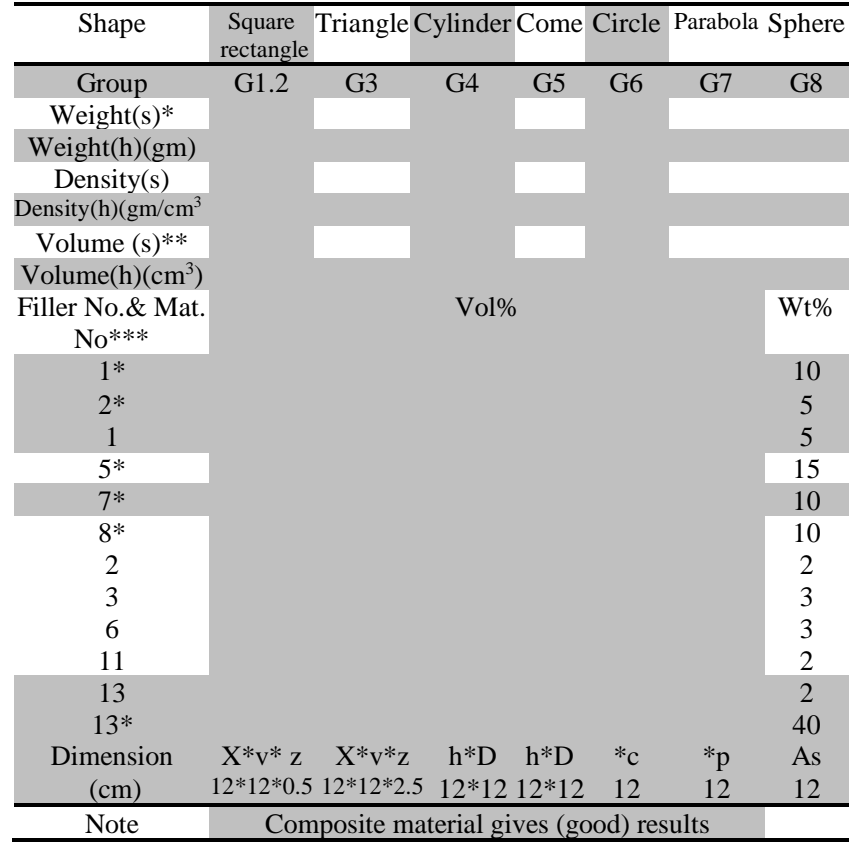


Table 8: Volumetric percentage of fillers of shape (K)

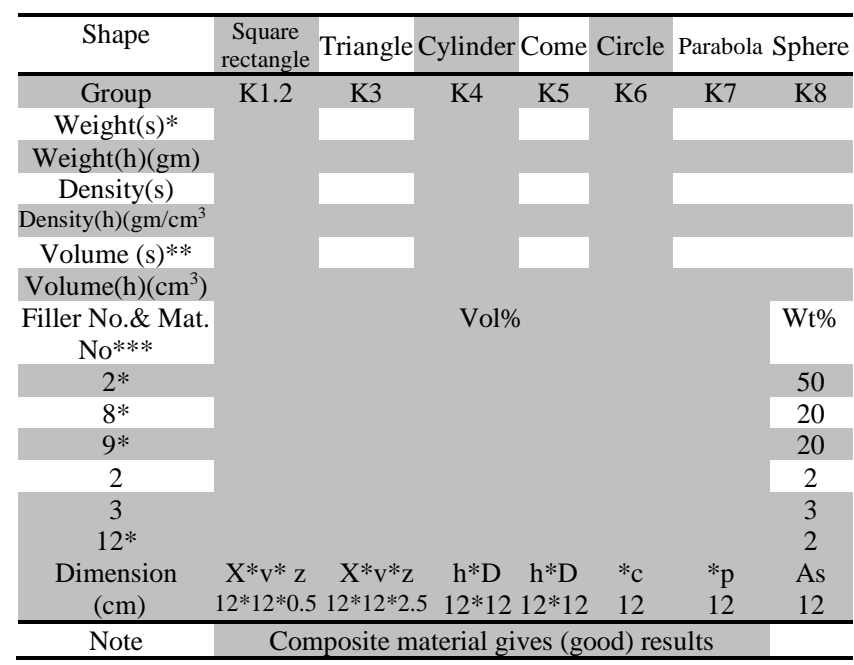

Table 9: Volumetric percentage of fillers of shape (L)

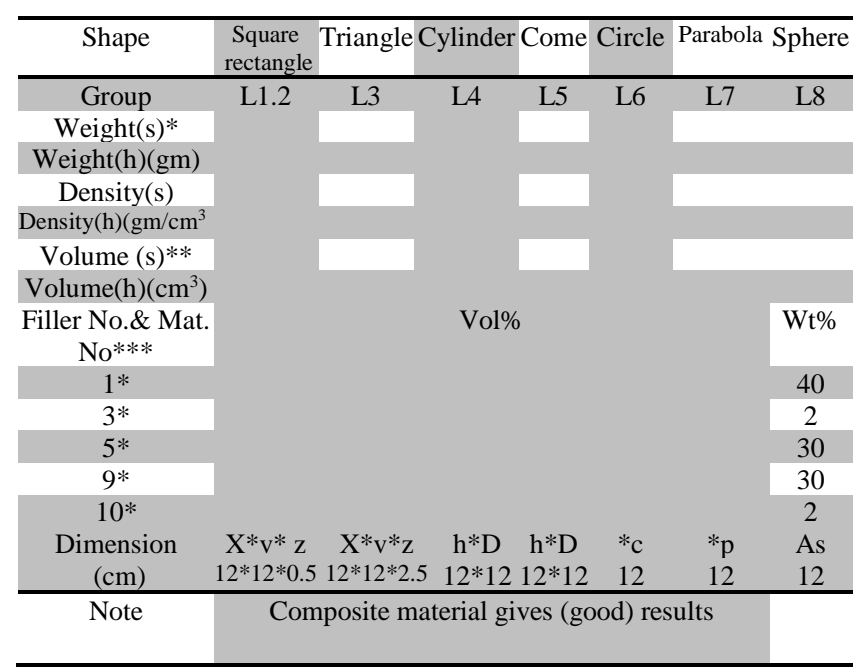

Table 10: Volumetric percentage of fillers of shape (M)

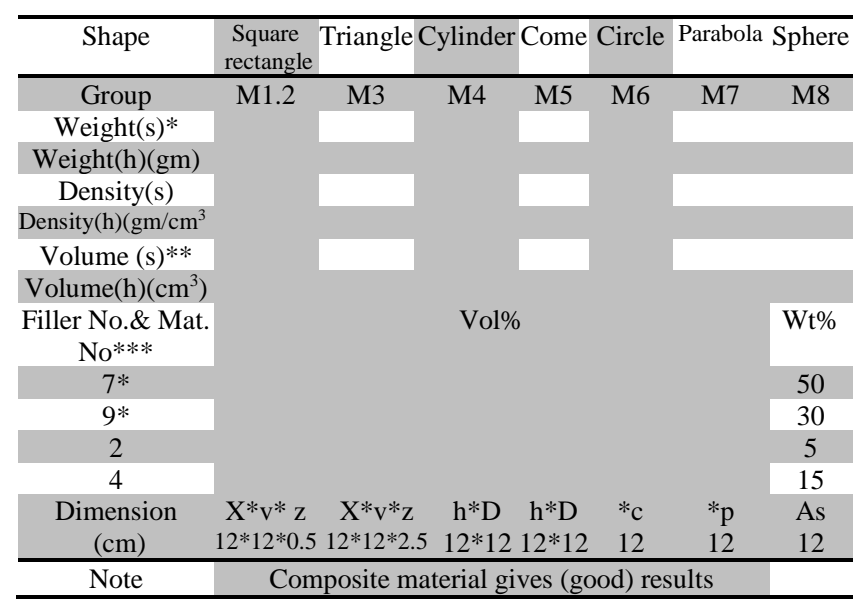

Table 12: Volumetric percentage of fillers of shape (O)

\begin{tabular}{|c|c|c|c|c|c|c|c|}
\hline Shape & $\begin{array}{l}\text { Square } \\
\text { rectangle }\end{array}$ & Triangle & Cylinder & Come & Circle & Parabola & Sphere \\
\hline Group & \multirow[t]{10}{*}{$\mathrm{O} 1.2$} & $\mathrm{O} 3$ & \multirow[t]{7}{*}{$\mathrm{O} 4$} & $\mathrm{O} 5$ & \multirow[t]{10}{*}{ O6 } & $\mathrm{O} 7$ & $\mathrm{O} 8$ \\
\hline Weight(s)* & & & & & & & \\
\hline Weight(h)(gm) & & & & & & & \\
\hline Density(s) & & & & & & & \\
\hline Density $(\mathrm{h})\left(\mathrm{gm} / \mathrm{cm}^{3}\right.$ & & & & & & & \\
\hline Volume (s)** & & & & & & & \\
\hline Volume $(\mathrm{h})\left(\mathrm{cm}^{3}\right)$ & & & & & & & \\
\hline $\begin{array}{c}\text { Filler No.\& Mat. } \\
\text { No*** }\end{array}$ & & & \multirow{3}{*}{\multicolumn{2}{|c|}{ Vol $\%$}} & & & $\mathrm{Wt} \%$ \\
\hline $1 *$ & & & & & & & 60 \\
\hline 1 & & & & & & & 10 \\
\hline
\end{tabular}

\begin{tabular}{cccccccc}
\hline $4 *+11 *+33$ & & & & 2 \\
$9 *$ & & & & & 30 \\
Dimension & $\mathrm{X}^{*} \mathrm{v} * \mathrm{z}$ & $\mathrm{X} * \mathrm{v} * \mathrm{z}$ & $\mathrm{h} * \mathrm{D}$ & $\mathrm{h} * \mathrm{D}$ & $* \mathrm{c}$ & $* \mathrm{p}$ & As \\
$(\mathrm{cm})$ & $12 * 12 * 0.5$ & $12 * 12 * 2.5$ & $12 * 12$ & $12 * 12$ & 12 & 12 & 12 \\
\hline Note & \multicolumn{2}{c}{ Composite material gives (good) results } \\
\hline
\end{tabular}

Table 13: Volumetric percentage of fillers of shape $(\mathrm{P})$

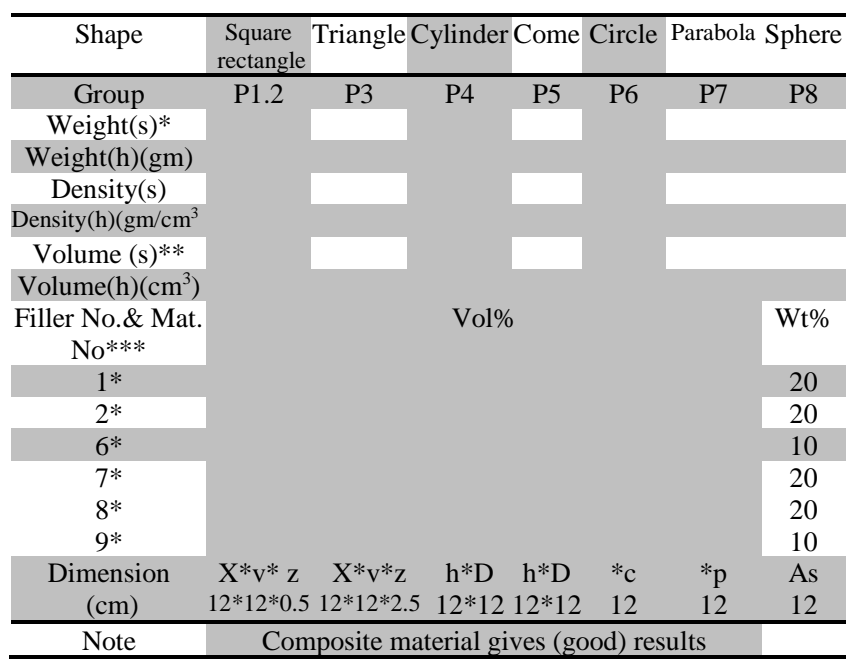

Table 14: Volumetric percentage of fillers of shape (Q)

\begin{tabular}{|c|c|c|c|c|c|c|c|}
\hline Shape & $\begin{array}{l}\text { Square } \\
\text { rectangle }\end{array}$ & Triangle $\mathrm{C}$ & Cylinder & Come & Circle & Parabola & Sphere \\
\hline Group & \multirow[t]{15}{*}{ Q1.2 } & Q3 & \multirow[t]{7}{*}{ Q4 } & Q5 & \multirow[t]{15}{*}{ Q6 } & \multirow[t]{2}{*}{ Q7 } & \multirow[t]{2}{*}{ Q8 } \\
\hline Weight(s)* & & & & & & & \\
\hline \multicolumn{5}{|l|}{ Weight(h)(gm) } & & & \\
\hline \multicolumn{5}{|l|}{ Density(s) } & & & \\
\hline \multicolumn{5}{|l|}{ Density $(\mathrm{h})\left(\mathrm{gm} / \mathrm{cm}^{3}\right.$} & & & \\
\hline \multicolumn{5}{|l|}{ Volume (s)** } & & & \\
\hline \multicolumn{5}{|l|}{ Volume(h) $\left(\mathrm{cm}^{3}\right)$} & & & \\
\hline $\begin{array}{c}\text { Filler No.\& Mat } \\
\text { No*** }\end{array}$ & & \multicolumn{3}{|c|}{ Vol\% } & & & $\mathrm{Wt} \%$ \\
\hline $2 *$ & & & & & & & 20 \\
\hline $3 *$ & & & & & & & 2 \\
\hline $5^{*}$ & & & & & & & 10 \\
\hline $6^{*}$ & & & & & & & 10 \\
\hline $7 *$ & & & & & & & 10 \\
\hline $8^{*}$ & & & & & & & 5 \\
\hline $9 *$ & & & & & & & 35 \\
\hline Dimension & $\mathrm{X}^{*} \mathrm{v}^{*} \mathrm{z}$ & $\mathrm{X} * \mathrm{v} * \mathrm{z}$ & $h * D$ & $h * D$ & $*_{\mathrm{c}}$ & $* \mathrm{p}$ & As \\
\hline$(\mathrm{cm})$ & $12 * 12 * 0.5$ & $12 * 12 * 2.5$ & $12 * 12$ & $12 * 12$ & 12 & 12 & 12 \\
\hline Note & Con & iposite ma & aterial gi & ves $(\mathrm{gc}$ & od) res & ults & \\
\hline
\end{tabular}

Table 15: Volumetric percentage of fillers of shape (J)

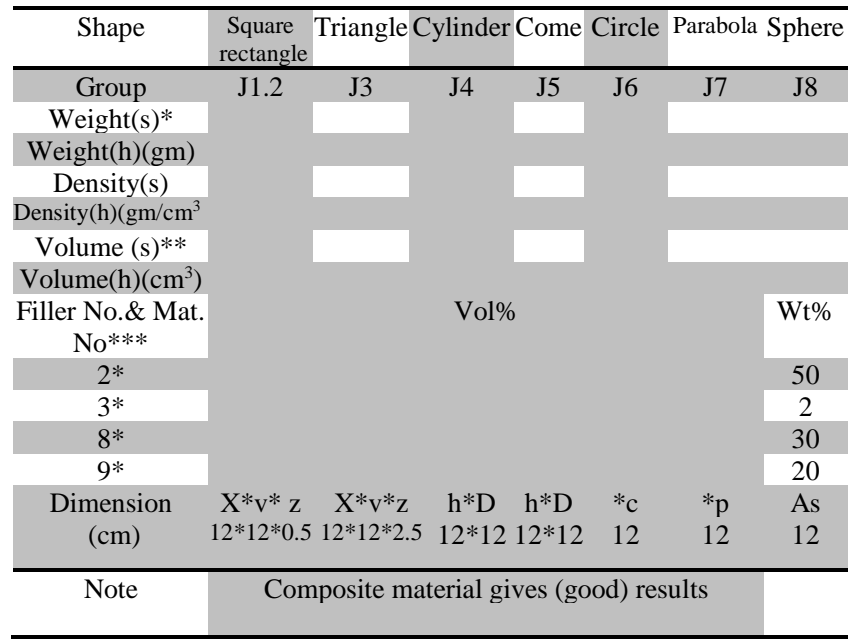

Table 16: Volumetric percentage of fillers of shape (T)

\begin{tabular}{|c|c|c|c|c|c|c|}
\hline Shape & $\begin{array}{c}\text { Square } \\
\text { rectangle }\end{array}$ & Triangle & Cylinder & r Come & Circle & Parabola Sphere \\
\hline Group & T1.2 & T3 & $\mathrm{T} 4$ & $\mathrm{~T} 5$ & $\overline{\text { T6 }}$ & T8 \\
\hline Weight(s)* & & & & & & \\
\hline
\end{tabular}




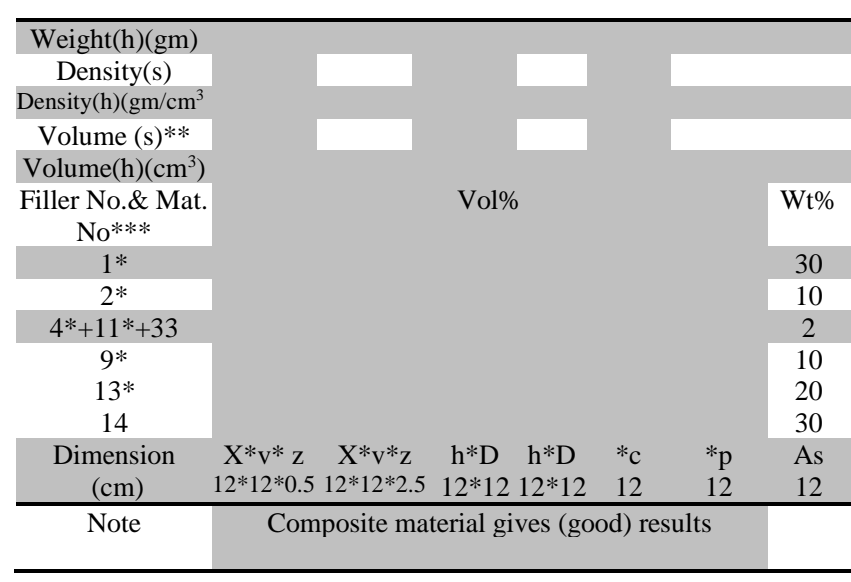

Table 17: Volumetric percentage of fillers of shape (R)

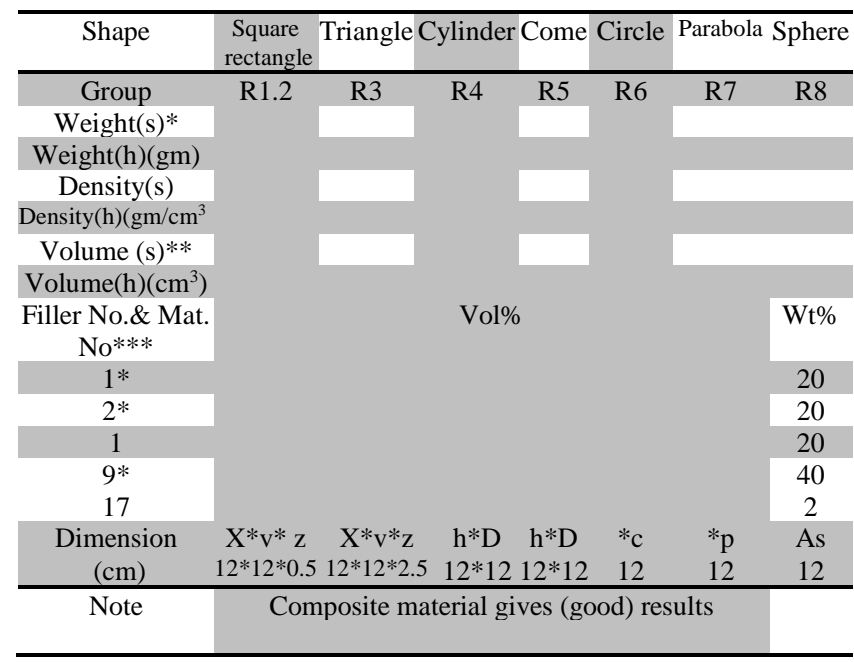

Table 18: Volumetric percentage of fillers of shape (S)

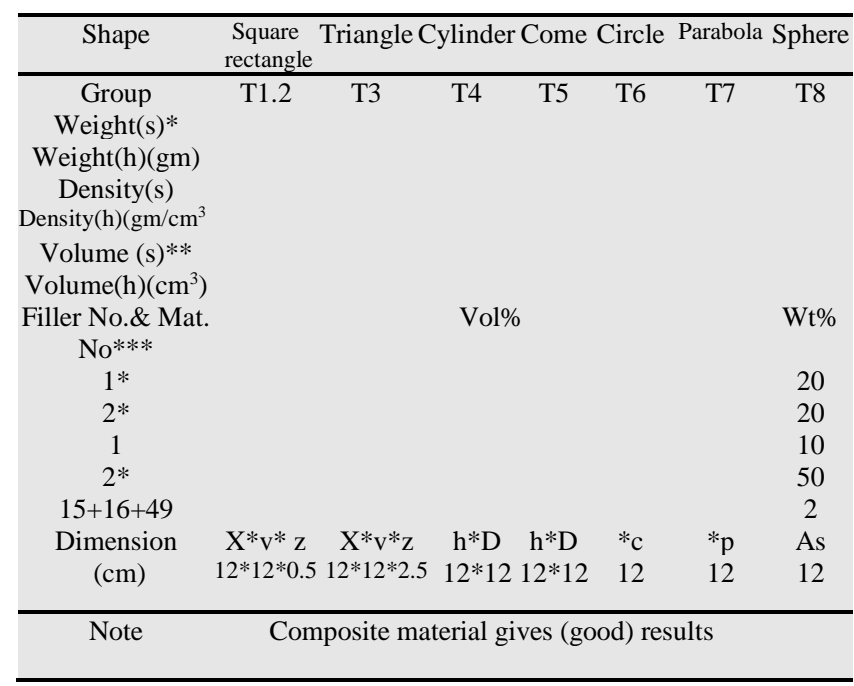

Table 19: Volumetric percentage of fillers of shape (V)

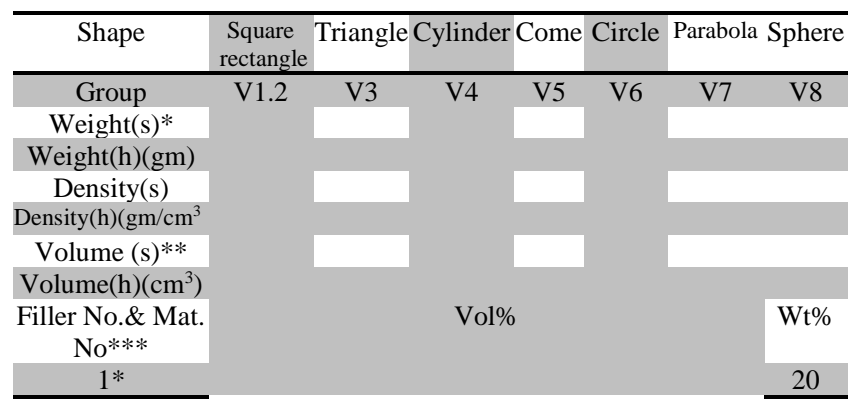

\begin{tabular}{|c|c|c|c|c|}
\hline $2 *$ & & & & 20 \\
\hline 1 & & & & 10 \\
\hline $5^{*}$ & & & & 10 \\
\hline $9 *$ & & & & 30 \\
\hline 6 & & & & 10 \\
\hline $15+16+49$ & & & & 2 \\
\hline Dimension & $h * D \quad h * D$ & $* \mathrm{c}$ & $* \mathrm{p}$ & As \\
\hline$(\mathrm{cm})$ & $12 * 12 * 0.5 \quad 12 * 12 * 2.5 \quad 12 * 1212 * 12$ & 12 & 12 & 12 \\
\hline Note & \multicolumn{3}{|c|}{ Composite material gives (good) results } & \\
\hline
\end{tabular}

Table 20: Volumetric percentage of fillers of shape $(\mathrm{X})$

\begin{tabular}{|c|c|c|c|c|c|c|c|}
\hline Shape & $\begin{array}{l}\text { Square } \\
\text { rectangle }\end{array}$ & Triangle C & Cylinder & Come & Circle & Parabola & Sphere \\
\hline Group & \multirow[t]{18}{*}{$\mathrm{X} 1.2$} & $\mathrm{X} 3$ & \multirow[t]{7}{*}{$\mathrm{X} 4$} & \multirow[t]{2}{*}{$\mathrm{X} 5$} & \multirow[t]{7}{*}{$\mathrm{X6}$} & \multirow[t]{2}{*}{$\mathrm{X7}$} & \multirow[t]{2}{*}{$\mathrm{X} 8$} \\
\hline Weight(s)* & & & & & & & \\
\hline \multicolumn{5}{|l|}{ Weight(h)(gm) } & & & \\
\hline \multicolumn{5}{|l|}{ Density(s) } & & & \\
\hline \multicolumn{5}{|l|}{ Density $(\mathrm{h})\left(\mathrm{gm} / \mathrm{cm}^{3}\right.$} & & & \\
\hline \multicolumn{5}{|l|}{ Volume $(\mathrm{s})^{* *}$} & & & \\
\hline \multicolumn{5}{|l|}{ Volume $(\mathrm{h})\left(\mathrm{cm}^{3}\right)$} & & & \\
\hline $\begin{array}{c}\text { Filler No.\& Mat. } \\
\text { No**** }\end{array}$ & & \multicolumn{3}{|c|}{ Vol\% } & & & $\mathrm{Wt} \%$ \\
\hline $1 *$ & & & & & & & 5 \\
\hline $2 *$ & & & & & & & 15 \\
\hline 1 & & & & & & & 2 \\
\hline $5^{*}$ & & & & & & & 3 \\
\hline $9 *$ & & & & & & & 10 \\
\hline 6 & & & & & & & 10 \\
\hline 13 & & & & & & & 5 \\
\hline $13 *$ & & & & & & & 40 \\
\hline $15+16$ & & & & & & & 2 \\
\hline 15 or 19 & & & & & & & 2 \\
\hline Dimension & $\mathrm{X}^{*} \mathrm{~V}^{*} \mathrm{z}$ & $\mathrm{X}^{*} \mathrm{v}^{*} \mathrm{z}$ & $\mathrm{h} * \mathrm{D}$ & $h * D$ & $*_{\mathrm{c}}$ & $* p$ & As \\
\hline$(\mathrm{cm})$ & $12 * 12 * 0.5$ & $12 * 12 * 2.5$ & $12 * 12$ & $12 * 12$ & 12 & 12 & 12 \\
\hline Note & Com & posite mat & terial gi & ives (go & od) res & sults & \\
\hline
\end{tabular}

Table 21: Volumetric percentage of fillers of shape (W)

\begin{tabular}{|c|c|c|c|c|c|c|c|}
\hline Shape & $\begin{array}{c}\text { Square } \\
\text { rectangle }\end{array}$ & Triangle $\mathrm{C}$ & ylinder & Come & Circle & Parabola & Sphere \\
\hline $\begin{array}{c}\text { Group } \\
\text { Weioht }(\mathrm{s}) *\end{array}$ & $\mathrm{~W} 1.2$ & W3 & W4 & W5 & W6 & W7 & W8 \\
\hline Weight(h)(gm) & & & & & & & \\
\hline Density(s) & & & & & & & \\
\hline Density $(\mathrm{h})\left(\mathrm{gm} / \mathrm{cm}^{3}\right.$ & & & & & & & \\
\hline Volume $(\mathrm{s})^{* *}$ & & & & & & & \\
\hline Volume $(\mathrm{h})\left(\mathrm{cm}^{3}\right)$ & & & & & & & \\
\hline Filler No.\& Mat. & & & Vol\% & & & & $\mathrm{Wt} \%$ \\
\hline No*** & & & & & & & \\
\hline $1 *$ & & & & & & & 30 \\
\hline $3 *$ & & & & & & & 2 \\
\hline 1 & & & & & & & 5 \\
\hline $6^{*}$ & & & & & & & 10 \\
\hline $7 *$ & & & & & & & 25 \\
\hline $9 *$ & & & & & & & 10 \\
\hline 4 & & & & & & & 10 \\
\hline 5 & & & & & & & 10 \\
\hline $15+16$ & & & & & & & 2 \\
\hline 18 or 19 & & & & & & & 2 \\
\hline Dimension & $\mathrm{X}^{*} \mathrm{v}^{*} \mathrm{z}$ & $\mathrm{X}^{*} \mathrm{v} * \mathrm{z}$ & $h * D$ & $\mathrm{~h} * \mathrm{D}$ & $*_{\mathrm{c}}$ & $* \mathrm{p}$ & As \\
\hline$(\mathrm{cm})$ & $12 * 12 * 0.5$ & $12 * 12 * 2.5$ & $12 * 12$ & $12 * 12$ & 12 & 12 & 12 \\
\hline Note & Com & posite mat & terial gi & ves (go & od) re & ults & \\
\hline
\end{tabular}


Table 22: Composition of samples (A-W) with matrices

\begin{tabular}{lcccccccccccccc}
\hline No Sample & $1^{*}$ & $2^{*}$ & $3^{*}$ & $4^{*}$ & $5^{*}$ & $6^{*}$ & $7 *$ & $8^{*}$ & $9^{*}$ & $10^{*} 11^{*} 12^{*}$ & $13^{*}$ \\
\hline A & 20 & - & 2 & 2 & 20 & - & 20 & 20 & - & - & - & - & - \\
B & - & - & - & - & 5 & 5 & 2.5 & 2.5 & - & - & - & - & 40 \\
C & - & 10 & 2 & - & - & - & - & - & - & - & - & - & 45 \\
D & - & 10 & - & - & - & 10 & - & 25 & 40 & - & - & - & - \\
E & 20 & - & - & - & 20 & - & - & - & 20 & - & - & - & - \\
F & - & 10 & - & - & - & 10 & 15 & - & - & - & - & - & 40 \\
G & 10 & 5 & - & - & 15 & - & 10 & 10 & - & - & - & - & 40 \\
K & - & 50 & - & - & - & - & - & 20 & 20 & - & - & 2 & - \\
L & 40 & - & 2 & - & 30 & - & - & - & 30 & 2 & - & - & - \\
M & - & - & - & - & - & - & 50 & - & 30 & - & - & - & - \\
N & 50 & - & - & - & 20 & - & - & - & - & - & - & - & - \\
O & 60 & - & - & 2 & - & - & - & - & 30 & - & 2 & - & - \\
P & 20 & 20 & - & - & - & 10 & 20 & 20 & 10 & - & - & - & - \\
Q & - & 20 & 2 & - & 10 & 10 & 10 & 5 & - & - & - & - & - \\
J & - & 50 & 2 & - & - & - & - & 30 & 20 & - & - & - & - \\
T & 30 & 10 & - & 2 & - & - & - & - & 10 & - & 2 & - & 20 \\
R & 20 & 20 & - & - & - & - & - & - & 40 & - & - & - & - \\
S & 20 & 20 & - & - & - & - & - & 50 & - & - & - & - & - \\
V & 2 & 20 & - & - & 10 & - & - & - & 10 & - & - & - & - \\
X & 5 & - & - & - & 2 & - & - & 3 & 10 & - & - & - & 40 \\
W & 30 & - & 2 & - & - & 10 & 25 & - & 10 & - & - & - & - \\
& & & & & & & & & & & \\
& & & & & & & & & & & & \\
& & & & & & & & & & & &
\end{tabular}

Table 23: Composition of samples (A-W) with Fillers

\begin{tabular}{|c|c|c|c|c|c|c|c|c|c|c|c|c|c|}
\hline $\begin{array}{c}\text { No } \\
\text { sample }\end{array}$ & 1 & 23 & 45 & 6 & 7 & 8 & $\begin{array}{ll}9 & 10\end{array}$ & 11 & 13 & 15 & 16 & 18 & 19 \\
\hline A & 10 & & & & & & & & & & & & \\
\hline B & 10 & & & 5 & 10 & 10 & & 2 & 5 & & & & \\
\hline $\mathrm{C}$ & 15 & & 1010 & 5 & & & & 2 & & & & & \\
\hline D & & & & & & & & & & & & & \\
\hline E & & & & & & & & & & & & & \\
\hline $\mathrm{F}$ & 15 & & & & & & 1010 & 2 & & 2 & 2 & & \\
\hline G & 5 & 23 & & 3 & & & & 2 & 5 & & & & \\
\hline $\mathrm{K}$ & & 23 & & & & & & & & & & & \\
\hline $\mathrm{L}$ & & & & & & & & & & & & & \\
\hline M & & 5 & 15 & & & & & & & & & & \\
\hline $\mathrm{N}$ & & & & 10 & & & & & & & & & \\
\hline $\mathrm{O}$ & 10 & & & & & & & & & & & & \\
\hline $\mathrm{P}$ & & & & & & & & & & & & & \\
\hline Q & & 5 & & & & & & & & & & & \\
\hline $\mathrm{J}$ & & & & & & & & & & & & & \\
\hline $\mathrm{T}$ & & & & & & & & & & & & & \\
\hline $\mathrm{R}$ & & & & & & & & & & & & & \\
\hline $\mathrm{S}$ & 10 & & & 10 & & & & & & 2 & 2 & & \\
\hline V & 10 & & & 10 & & & & & & 2 & 2 & & \\
\hline $\mathrm{X}$ & 15 & & & & & & & & 5 & 2 & 2 & 2 & 2 \\
\hline W & 5 & & 1010 & & & & & & & 2 & 2 & & 2 \\
\hline
\end{tabular}

Table 24: Gain, power ratio of fillers

\begin{tabular}{|c|c|c|c|c|c|}
\hline No & Matrix & $\begin{array}{l}\text { Gain } \\
(-\mathrm{db}) \\
\end{array}$ & $\begin{array}{c}\text { Power } \\
\text { Ratio }\end{array}$ & $\begin{array}{c}\propto \mathrm{e}^{*} \\
(\mathrm{~m}-1)\end{array}$ & Vol\% \\
\hline 1 & Graphite & 7.5 & 0.18 & 1.7 & $100 \%$ \\
\hline 2 & Fe-powder & 2 & 0.63 & 0.46 & $=$ \\
\hline 3 & Al-powder & 3 & 0.5 & 0.63 & $=$ \\
\hline 4 & Fe-fibers & 4 & 0.39 & 0.94 & $=$ \\
\hline 5 & Al-Fibers & 4 & 0.39 & 0.94 & $=$ \\
\hline 6 & Glass powder & 6 & 0.25 & 1.3 & $=$ \\
\hline 7 & Fe-panels & 2 & 0.63 & 0.46 & $=$ \\
\hline 8 & Ai-panels & 2 & 0.63 & 0.46 & $=$ \\
\hline 9 & Fe-pins & 2 & 0.63 & 0.46 & $=$ \\
\hline 10 & Al-pins & 2 & 0.63 & 0.46 & $\ldots \ldots$ \\
\hline 11 & Fiber glass & 10 & 0.1 & 2.3 & $100 \%$ \\
\hline 12 & Glass grains & 6 & 0.25 & 1.3 & $=$ \\
\hline 13 & Magnetpieces & 6 & 0.25 & 1.36 & $=$ \\
\hline 14 & Fe-dishes & 1.5 & 0.1 & 0.35 & $\ldots \ldots$ \\
\hline 15 & Small sq. and hexa. lattices & 0.5 & 0.89 & 0.11 & $\ldots \ldots$ \\
\hline 16 & Square and hexa. latices & 0.5 & 0.89 & 0.11 & ....... \\
\hline 17 & Al-sq lattices & 0.5 & 0.89 & 0.11 & $\ldots$ \\
\hline 18 & Fe-rect lattices & 0.5 & 0.89 & 0.11 & $\ldots \ldots$ \\
\hline 19 & Ai-rect lattices & 0.5 & 0.89 & 0.11 & $\ldots \ldots$ \\
\hline
\end{tabular}

Table 25: Gain, power ratio of fillers

\begin{tabular}{cl}
\hline No & \multicolumn{1}{c}{ Fillers } \\
\hline 1 & Graphite powder $(\mathrm{d}=0.1 \mathrm{~mm})$ \\
2 & Iron powder Fe-powder $(\mathrm{d}=0.1 \mathrm{~mm})$ \\
3 & Aluminum powder Al-powder $(\mathrm{d}=0.1 \mathrm{~mm})$ \\
4 & Iron fibers, Fe-fibers [L $9-11 \mathrm{~cm}, \mathrm{~d} 1 \mathrm{~mm}$ \\
5 & Aluminum fibers Al-Fibers [L $9-11 \mathrm{~cm}, \mathrm{~d} 1 \mathrm{~mm}]$ \\
6 & Glass powder $(\mathrm{d}=0.1 \mathrm{~mm})$ \\
7 & Iron panels Fe-panels $(9-10 \mathrm{~cm}, \mathrm{~d}=1 \mathrm{~mm}]$ \\
8 & Aluminum panels Al-panels [9-11 cm, d= $1 \mathrm{~mm}]$ \\
9 & Iron pins ; Fe - pins $\{\mathrm{L}=2.5 \mathrm{~cm}, \mathrm{~d}=1 \mathrm{~mm}\}$ \\
10 & Aluminum pins Ai-pins $[\mathrm{L}=2.5 \mathrm{~cm}, \mathrm{~d}=1 \mathrm{~mm})$ \\
11 & Fiber glass (Layer 10-10cm, Thick=3mm] \\
12 & Glass particles [d $\approx \quad 10 \mathrm{~mm})$ \\
13 & Magnet pieces Id $\approx \quad 10 \mathrm{~mm}]$ \\
14 & Iron dish with holes ; Fe-dishes $\left[{ }^{\mathrm{d}} \mathrm{d}=10 \mathrm{~cm},{ }^{\mathrm{d}} \mathrm{h}=5 \mathrm{~mm}\right)$ \\
15 & Square iron lattice $(2.45-2.45 \mathrm{~cm})$ and hexagonal lattice $(2.45-2.4 \mathrm{Scm})$ \\
16 & Square iron lattices $(3.75-3.75 \mathrm{~cm})$ and hexagonal lattice $(3.75-3.7 \mathrm{Scm})$ \\
17 & Aluminium square iattic $(2.45-2.45 \mathrm{~cm}),(3.75-3.75 \mathrm{~cm})$ \\
18 & Iron rectangular lattice $(3.75-2.45 \mathrm{~cm})$ \\
19 & Aluminum and rectangular lattice $(3.75-2.45 \mathrm{~cm})$ \\
\hline
\end{tabular}

Table 26: Attenuation (gain), power ratio and absorption coefficient of

\begin{tabular}{ll}
\multicolumn{1}{c}{ matrixes } \\
\hline No & \multicolumn{1}{c}{ Matrixes } \\
\hline $1 *$ & Low density poly (463), L.D.P.E $(463)$ \\
$2 *$ & High density polyethylene \\
$3 *$ & Adhesion \\
$4 *$ & Light plastic cover Thick $0.25 \mathrm{~mm}),($ A $1010 \mathrm{~cm})$ \\
$5 *$ & Polyvinyl chloride, P. V. C (667) \\
$6 *$ & Low density polyethylene (M.B) \\
$7 *$ & Polyviny chloride (normal) \\
$8 *$ & Polyvinyl chloride (blue) \\
$9 *$ & Plymide (red) \\
$10 *$ & Light oil \\
$11 *$ & Thick plastic cover I Thick $2 \mathrm{~mm}),(\mathrm{A} .10-10 \mathrm{~cm})]$ \\
$12 *$ & Thick layer of phillene t(Thick-5mm), (A $1010 \mathrm{~cm})$ Polyterafluoro- \\
& ethylene (P.T.F.E) \\
$13 *$ & Poly tetraflouride ethylene
\end{tabular}

Table 27: Attenuation (gain), power ratio and absorption coefficient of main matrixes (standard power 300mw)

\begin{tabular}{|c|c|c|c|c|c|}
\hline No & Matrix & Gain(-db) & Power Ratio & $\alpha \boldsymbol{e}^{*}\left(\mathrm{~m}^{-1}\right)$ & Vol \% \\
\hline $1 *$ & L. D.P.E (463) & 5 & 0.32 & 1.1 & $100 \%$ \\
\hline $2 *$ & H.D.P.E & 6.5 & 0.22 & 1.5 & $=$ \\
\hline $3 *$ & Adhesion & 10 & 0.1 & 2.3 & $=$ \\
\hline $4^{*}$ & Light plastic cover & 10 & 0.1 & 2.3 & ..... \\
\hline $5^{*}$ & P.V.C (667) & 7.5 & 0.18 & 1.7 & $100 \%$ \\
\hline $6^{*}$ & L. D.P.E (M.B) & 5.5 & 0.28 & 1.2 & $=$ \\
\hline $7 *$ & P. V.C (normal & 7 & 0.2 & 1.6 & $=$ \\
\hline $8^{*}$ & P. V. C (blue) & 7 & 0.2 & 1.6 & $-=$ \\
\hline $9 *$ & P. A (red) & 8 & 0.16 & 1.8 & $=$ \\
\hline $10 *$ & Light special oil & 8 & 0.16 & 1.8 & $=$ \\
\hline $11 *$ & Thich plastic cover & 10 & 0.1 & 2.3 & $\ldots .$. \\
\hline $12 *$ & Thick phillene layer & 5 & 0.32 & 1.1 & $\ldots$ \\
\hline $13 *$ & P.T.F.E & 9 & 0.13 & 2.04 & $100 \%$ \\
\hline
\end{tabular}

Table 28: Attenuation, power ratio, for mixture (polymer + filler)

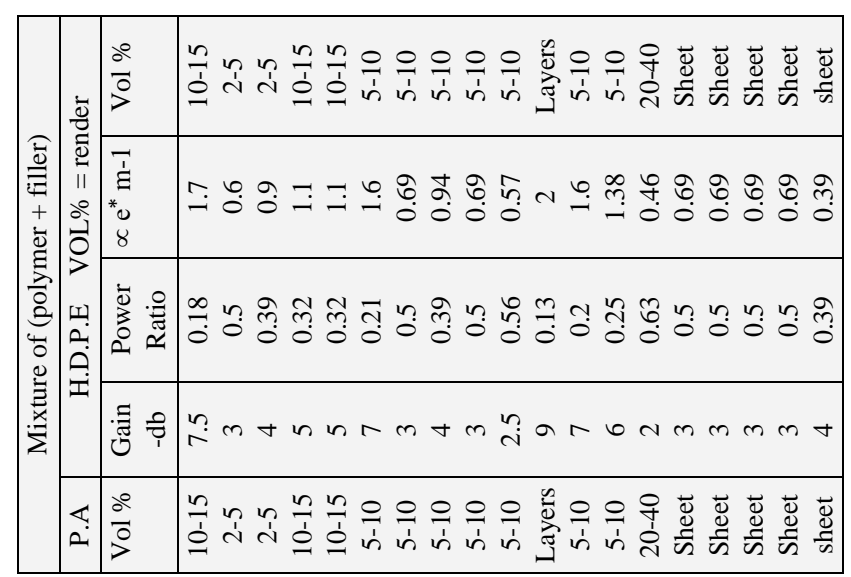




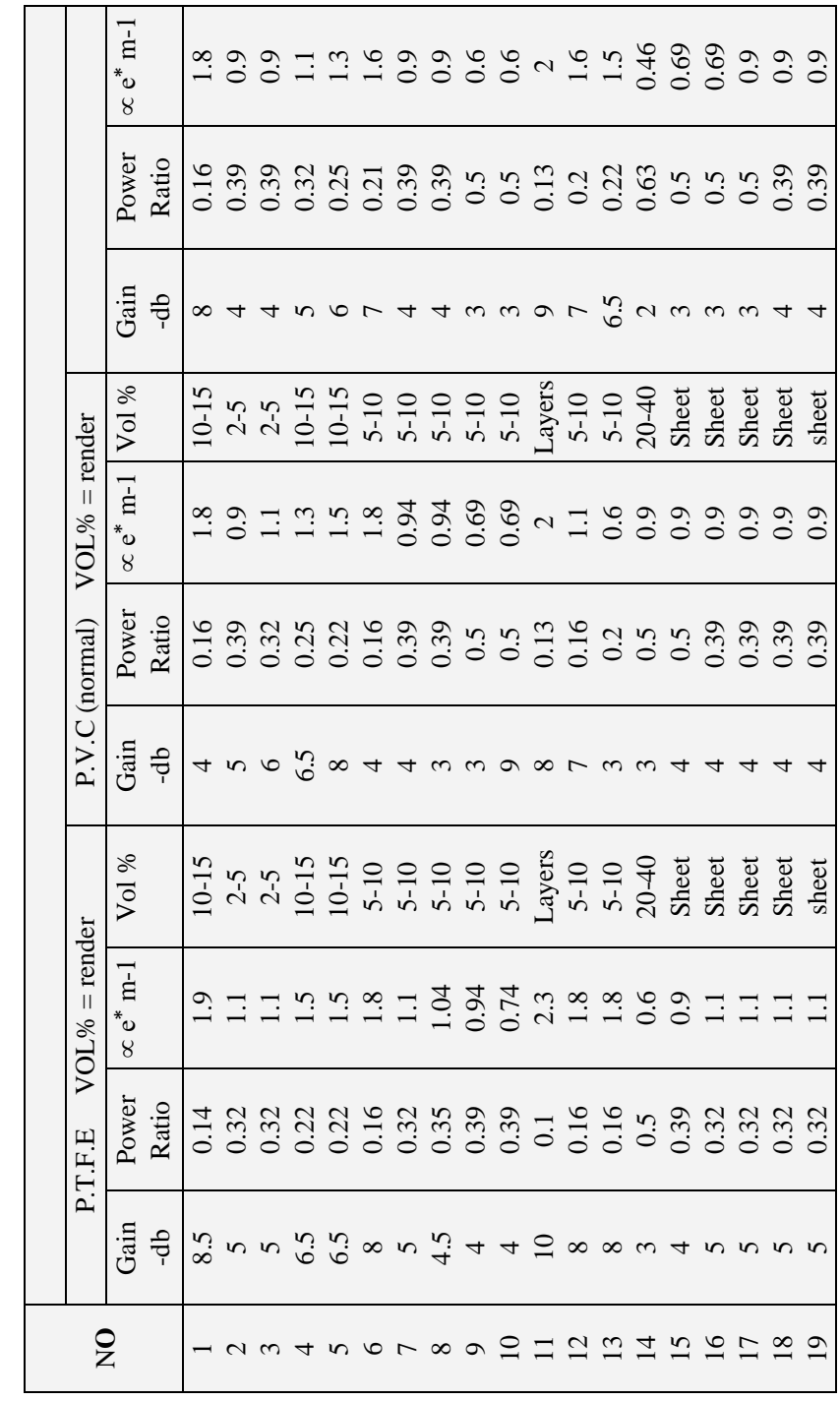

Table 29: Absorption cross section for different composite martials shapes

\begin{tabular}{|c|c|c|c|c|c|c|c|}
\hline Sample & $\begin{array}{c}(\alpha) \\
\text { Square } \\
\text { shape }\end{array}$ & $\begin{array}{c}(\alpha) \\
\text { Triangle } \\
\text { shape }\end{array}$ & $\begin{array}{c}(\alpha) \\
\text { Cylin- } \\
\text { drical } \\
\text { shape }\end{array}$ & $\begin{array}{c}(\alpha) \\
\text { Conical. } \\
\text { shape }\end{array}$ & $\begin{array}{c}(\alpha) \\
\text { Parabolic } \\
\text { shape }\end{array}$ & $\begin{array}{c}(\alpha) \\
\text { Spherical } \\
\text { shape }\end{array}$ & $\begin{array}{c}(\alpha) \\
\text { Circular } \\
\text { shape }\end{array}$ \\
\hline $\mathrm{A} / 1$ & 35 & $\mathbf{1 6 0}$ & 0.10 & 0.3 & 30 & 1.6 & 50 \\
\hline $\mathrm{B} / 2$ & 10 & $\mathbf{4 0}$ & 0.04 & 0.2 & 20 & 1 & 15 \\
\hline $\mathrm{C} / 3$ & 15 & $\mathbf{6 0}$ & 0.04 & 0.2 & 20 & 1 & 20 \\
\hline $\mathrm{D} / 4$ & 17 & $\mathbf{6 0}$ & 0.04 & 0.2 & 20 & 1 & 25 \\
\hline $\mathrm{E} / 5$ & 70 & $\mathbf{3 6 0}$ & 0.24 & 0.9 & 80 & 3.2 & 100 \\
\hline $\mathrm{F} / 6$ & 20 & $\mathbf{1 2 0}$ & 0.04 & 0.2 & 20 & 1 & 30 \\
\hline $\mathrm{G} / 7$ & $\mathbf{1 5}$ & $\mathbf{8 0}$ & 0.04 & 0.2 & 20 & 1 & 25 \\
\hline $\mathrm{K} / 8$ & $\mathbf{5 5}$ & $\mathbf{2 8 0}$ & 0.2 & 0.7 & 70 & 3 & 90 \\
\hline $\mathrm{L} / 9$ & $\mathbf{5 0}$ & $\mathbf{2 4 0}$ & 0.19 & 0.6 & 60 & 2 & 70 \\
\hline $\mathrm{M} / 10$ & $\mathbf{5 5}$ & $\mathbf{2 6 0}$ & 0.14 & 0.65 & 60 & 2 & 80 \\
\hline $\mathrm{N} / 11$ & $\mathbf{5 6}$ & $\mathbf{2 7 0}$ & 0.15 & 0.65 & 60 & 2 & 85 \\
\hline $\mathrm{O} / 12$ & $\mathbf{5 7}$ & $\mathbf{2 9 0}$ & 0.15 & 0.6 & 50 & 1.8 & 90 \\
\hline $\mathrm{P} / 13$ & $\mathbf{4 5}$ & $\mathbf{2 2 0}$ & 0.14 & 0.8 & 80 & 1 & 70 \\
\hline $\mathrm{Q} / 14$ & $\mathbf{4 5}$ & $\mathbf{3 6 0}$ & 0.24 & 0.7 & 70 & 1.5 & 110 \\
\hline $\mathrm{J} / 15$ & $\mathbf{8 0}$ & $\mathbf{3 0 0}$ & 0.2 & 0.6 & 60 & $\mathbf{1}$ & 90 \\
\hline $\mathrm{T} / 16$ & $\mathbf{5 0}$ & $\mathbf{2 8 0}$ & 0.2 & 0.6 & 50 & $\mathbf{1}$ & 80 \\
\hline $\mathrm{R} / 17$ & $\mathbf{3 0}$ & $\mathbf{1 8 0}$ & 0.12 & 0.6 & 20 & 1.5 & 40 \\
\hline $\mathrm{S} / 18$ & $\mathbf{1 0}$ & $\mathbf{2 0 0}$ & 0.14 & 0.2 & 30 & 1.5 & 60 \\
\hline $\mathrm{V} / 19$ & $\mathbf{2 5}$ & $\mathbf{1 2 0}$ & 0.09 & 0.3 & 20 & 1 & 40 \\
\hline $\mathrm{X} / 20$ & $\mathbf{1 0}$ & $\mathbf{5 0}$ & 0.04 & 0.2 & 20 & 1 & 60 \\
\hline $\mathrm{W} / 21$ & $\mathbf{7 0}$ & $\mathbf{3 6 0}$ & 0.24 & 0.3 & 30 & 1.6 & 100 \\
\hline & & & & & & & \\
\hline
\end{tabular}
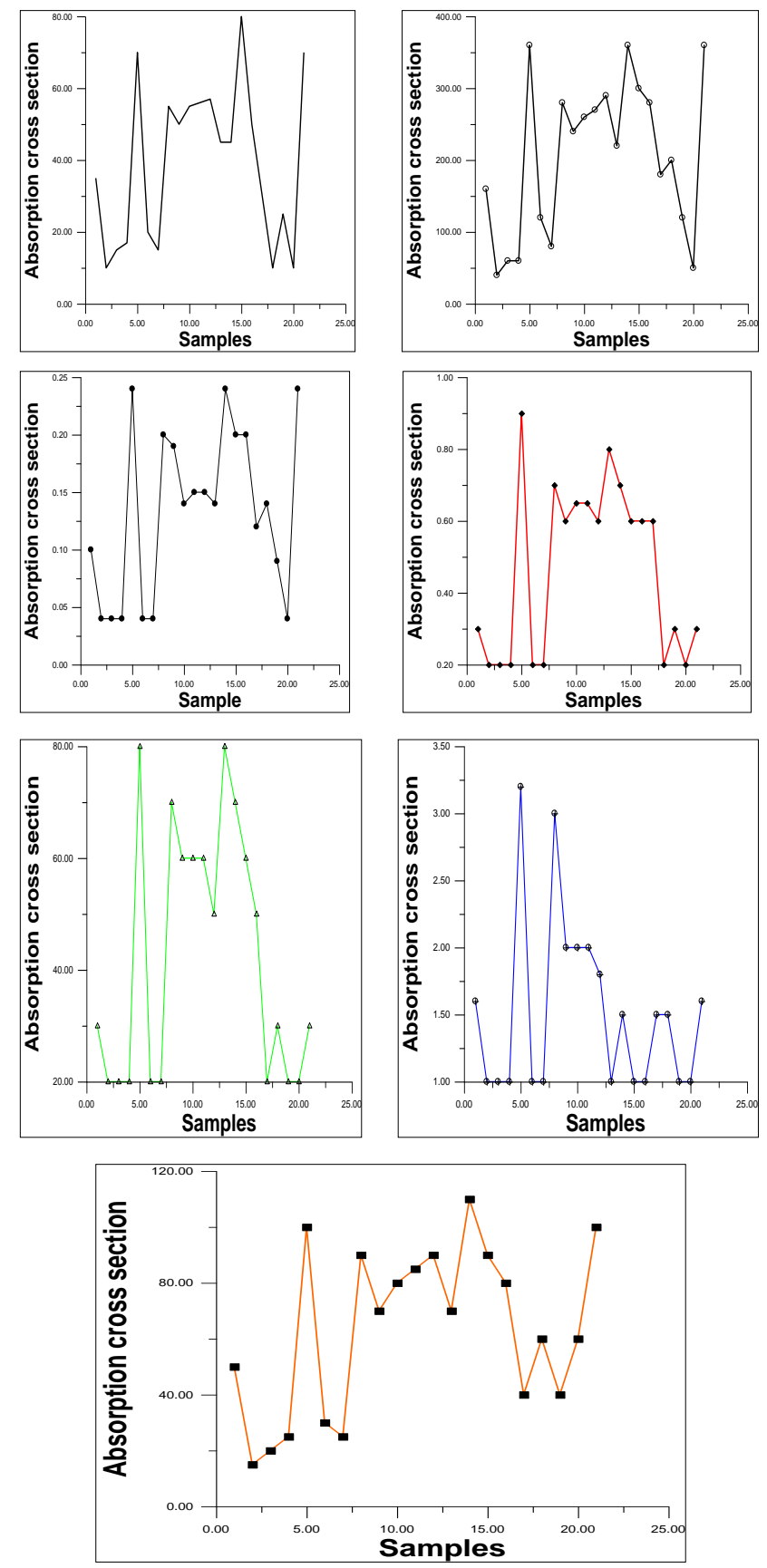

Fig. 6: Effect of coated layer on target cross section for differ

\section{Conclusion}

Target absorption cross section is in order of (70-100\%) of incident radar waves observed in present work. We see that (P.T.F.E) reinforced by fiber glass and addition of $(5-10 \%)$ graphite powder gave the highest attenuation of radar waves. We see also that the increasing in coating thickness has no effect on attenuation but causes an increase in airplane weight, therefore coating of $(0.5 \mathrm{~cm})$ with fillers and matrices used as an ideal thickness in this research. Samples prepared by spraying technique gives higher absorption than others formed by injection and other techniques.(P.T.F.E) with the mixture of $30 \%$ fiber glass gives the highest erosion resistance. For all cases, we see that the triangular shape is the proper design, i.e. produces higher attenuation.For same shape, we see that the higher absorption coefficient is at thickness equals to $(0.5 \mathrm{~cm})$ and W.L. $=3.75$ 


\section{Acknowledgement}

To all who help me in this research.

\section{References}

[1] Balanis,"Antenna theory: analysis and design". New York, USA: Wiley, 1997.

[2] Gerry, Potter, Gupta \& Van der Merwe, "A parametric model for syntheticaperture radar measurements". IEEE transactions on antenna and propagation.

[3] Haywood, Andersson, Morris \&Kyprianou, "Generation of point scatterer models for simulating ISAR images of ships". IEE Publication, No. 449, 1997.

[4] Knowbell Version 3 User's Guide," Information Systems and Research", Inc, 1997.

[5] Hughes \& Leyland M, "Using multiple genetic algorithms to generate radar point scatterer models". IEEE transactions on evolutionary computation, Vol. 4, No. 2, p.147- 163,2000.

[6] D.Fulghum, Stealth Retains Value, But its Monopoly Wanes, Aviation Week and Space technology, Feb. 5, 2001.

[7] Principle of a Pulsed Laser Sensor, http://www.riegl.co.at, 26/02/2001.

[8] BassemMahafza, "Radar Systems Analysis and Design Using MATLAB", 2nd Ed. Chapman \& Hall/CRC, 2005.

[9] N.Currie (ed), "Radar reflectivity Measurement", Techniques and Applications, Artech, 1989.

[10] D.barton, "Modern Radar Systems Analysis", Artech, 1988.

[11] M.Skolnik, "Introduction to Radar Systems", McGraw Hill, 1980.

[12] H.Durrant-Whyte, "Sensors and Signals Notes. Principle of a Pulsed Laser Sensor", http://www.riegl.co.at , 26/02/2001.

[13] Ahmad, A \& Ericsson, T.E., "Coarsening of S, TIS phase and mechanical properties of two Al-Li-Cu-Mg alloys", $3^{\text {rd }}$ Int. Al-Li conf, 1986, p. 509-515.

[14] Minamino, Y., Yamane, T. \& Araki, H., "Interdiffusion in a dilute solid solution of $\mathrm{Al}-\mathrm{Li}$ alloy measured by electrical resistance", Metall. Trans., vol. 18A, No.8, 1987, p.1536-38.

[15] Enrique, Lavernia\& Nicholas S. Grant, "Review AlluminiumLithium alloys" , J. Mat. sci., vol. 22, 1987, p. 1521- 1529.

[16] Karwi, Abbas Ali Mahmood," Mathematical Modeling of Detraction The Absorption of Microwaves Reflected from The Stationary Flight Testing Body" IECCMAS conference, 2018.

[17] Karwi, Abbas Ali Mahmood, "Change The Morphology of Lithium Oxides By Nd-Yag Laser Beam To Use as A sand in WaterCooled Reactors", 2018.

[18] [18] Karwi, Abbas Ali Mahmood, "Use of Detectors Technology for Gamma Ray Issued from Radioactive Isotopes and its Impact on Knowledge of Behavior of the Stationary Case of Solid Phase Holdup", World Academy of Science, Engineering and Technology, 2012.

[19] Karwi,Abbas Ali Mahmood, "Alignment of Emission Gamma Ray Sources with Nai(Ti) Scintillation Detectors by Two Laser Beams to Pre-Operation using Alternating Minimization Technique", World Academy of Science, Engineering and Technology, 2012.

[20] Karwi, Abbas Ali Mahmood, "Image of Multi Phase Phantoms Using Alternating Minimization Algorithm in Noninvasive Measurement Technique", Journal of Communication and Computer 9, 1269-1278, 2012.

[21] Karwi, Abbas Ali Mahmood, Abdullah Eman Mohammed, " Shielding Processing Technique through the Calculations and Measurement of the Time Averaged Cross-Section of Multiphase Domain", Global Journal of Researches in Engineering, Volume 12 Issue 3 Version 1.0, ISSN: 2249-4596 \& Print ISSN: 09755861, 2012.

[22] Karwi, Abbas Ali Mahmood, " Design System to Adsorb Soluble Metallic Ions Using Biomass Materials To Maintain The Safety and stability of The saturated Liquids", Kufa Journal of Engineering Vol. 9, No. 1, January 2018, PP. 91-105 Received 21 February 2017, accepted 8, May 2017.

[23] Karwi, Abbas Ali Mahmood, Eman Mohammed Abdullah," Empirical Study Heating Processes Effect on the Decay of Irradiation Radon Gas Products and Calculation the Optimal Benefit Cost", International Journal of Engineering Innovation \& Research Volume 4, Issue 3, ISSN: 2277 -5668.

[24] Karwi, Abbas Ali Mahmood, "Preparation Radioactive Particle Technique Used To Track the Motion of Oil Phase in High Pressure Tank", International Journal of Electronics Communication and Computer Engineering Volume 3, Issue 6, ISSN (Online): 2249-071X, ISSN (Print): 2278-4209.

[25] Karwi, Abbas Ali Mahmood," The Negative Harmful Effects of High Irradiation Gas Concentration Treated By Facility Designed and Use the Model of an Accounting Disclosure", International Journal of Research in Engineering and Social Sciences, ISSN 2249-9482, Impact Factor: 6.301, Volume 07 Issue 1, January 2017, Page 1-13.

[26] Karwi, Abbas Ali Mahmood, Eman Mohammed Abdullah, " Computed Tomography Used in Petroleum for Imaging Oil Phase During Runoff" ,MPC, The Twelfth Mediterranean Petroleum Conference and Exhibition, 2012. 